\title{
Response inhibition and attention processing in 5-to 7-year-old children with and without symptoms of ADHD: An ERP study
}

Citation for published version (APA):

Spronk, M., Jonkman, L. M., \& Kemner, C. (2008). Response inhibition and attention processing in 5-to 7year-old children with and without symptoms of ADHD: An ERP study. Clinical Neurophysiology, 119(12), 2738-2752. https://doi.org/10.1016/j.clinph.2008.09.010

Document status and date:

Published: 01/01/2008

DOI:

10.1016/j.clinph.2008.09.010

Document Version:

Publisher's PDF, also known as Version of record

Document license:

Taverne

Please check the document version of this publication:

- A submitted manuscript is the version of the article upon submission and before peer-review. There can be important differences between the submitted version and the official published version of record.

People interested in the research are advised to contact the author for the final version of the publication, or visit the DOI to the publisher's website.

- The final author version and the galley proof are versions of the publication after peer review.

- The final published version features the final layout of the paper including the volume, issue and page numbers.

Link to publication

\footnotetext{
General rights rights.

- You may freely distribute the URL identifying the publication in the public portal. please follow below link for the End User Agreement:

www.umlib.nl/taverne-license

Take down policy

If you believe that this document breaches copyright please contact us at:

repository@maastrichtuniversity.nl

providing details and we will investigate your claim.
}

Copyright and moral rights for the publications made accessible in the public portal are retained by the authors and/or other copyright owners and it is a condition of accessing publications that users recognise and abide by the legal requirements associated with these

- Users may download and print one copy of any publication from the public portal for the purpose of private study or research.

- You may not further distribute the material or use it for any profit-making activity or commercial gain

If the publication is distributed under the terms of Article 25fa of the Dutch Copyright Act, indicated by the "Taverne" license above, 


\title{
Response inhibition and attention processing in 5- to 7-year-old children with and without symptoms of ADHD: An ERP study
}

\author{
M. Spronk ${ }^{\mathrm{a}, *}$, L.M. Jonkman ${ }^{\mathrm{a}}$, C. Kemner ${ }^{\mathrm{a}, \mathrm{b}}$ \\ a Department of Cognitive Neuroscience, Faculty of Psychology, Maastricht University, P.O. Box 616, 6200 MD Maastricht, The Netherlands \\ ${ }^{\mathrm{b}}$ Department of Child and Adolescent Psychiatry, University Medical Centre, Utrecht, The Netherlands
}

\section{A R T I C L E I N F O}

\section{Article history:}

Accepted 8 September 2008

Available online 23 October 2008

\section{Keywords:}

Response inhibition

Attention

Event-related brain potentials

Attention-deficit hyperactivity disorder

Nogo-N2

Nogo-P3

\begin{abstract}
A B S T R A C T
Objective: Response inhibition and attention processing in 5- to 7-year-old children with or without symptoms of attention-deficit hyperactivity disorder (ADHD) were examined.

Methods: Twelve children with ADHD symptoms and 15 control children performed a CPT-AX task. Behavioral measures of inattention and impulsivity and ERP measures of conflict monitoring and inhibition (Nogo-N2 and Nogo-P3), cue-orientation and prestimulus target expectation (Cue-P2 and P3) and response preparation $(\mathrm{CNV})$ were collected.

Results: ADHD children detected fewer targets and had higher Inattention scores accompanied by reduced centro-parietal Cue- and Go-P3 activity. Occipital CNV amplitude was larger in ADHD children. At fronto-central leads, strong and comparable fronto-parietal Nogo-N2 effects were found in both groups, whereas the Nogo-P3 was only marginally significant in both groups.

Conclusions: The attenuated Cue- and Go-P3 effects in the ADHD-symptom group are interpreted as early signs of delayed attention development, resulting in less preparation and less alertness to detect significant events. Whereas the Nogo-N2 effects were interpreted as signs of comparable levels of conflict processing in both groups, the small Nogo-P3 suggests that inhibitory processing is still immature at this age. Significance: The present study shows that specific attention problems can already be detected in the behavior and brain activity of 5- to 7-year-old children with symptoms of ADHD performing a CPT-AX task, and might be better indicators for the risk of developing ADHD than impulsivity measures. (C) 2008 International Federation of Clinical Neurophysiology. Published by Elsevier Ireland Ltd. All rights
\end{abstract}

reserved.

\section{Introduction}

Attention-deficit hyperactivity disorder (ADHD) is the most common psychiatric disorder in children today, affecting $3-5 \%$ of all school-aged children (DSM-IV, American Psychiatric Association, 1994). Displaying symptoms such as hyperactivity, impulsiveness and inattention, ADHD interferes with many areas of normal functioning and can severely affect normal development. For these reasons the disorder has been given much attention in recent research.

While the behavioral impairments characteristic for ADHD are well known, there's still no consensus on the underlying nature and neural basis of this disorder. Barkley (1997) suggested that the impairments seen in ADHD are due to problems of executive functioning (EF) caused by impairments in behavioral inhibition. Behavioral inhibition refers to the ability to actively suppress or interrupt an activated response, and in recent years its development has been linked to the development of a network of fron-

\footnotetext{
* Corresponding author. Tel.: +31 43388 4535; fax: +31 433884125 .

E-mail address: Marjolein.Spronk@psychology.unimaas.nl (M. Spronk).
}

tal-striatal areas in the brain (Vaidya et al., 1998; Casey et al., 2005). Since frontal areas are not yet fully developed in childhood, children often perform worse on tasks measuring executive functions, and compared to adults they recruit larger, more diffuse prefrontal regions when performing cognitive control demanding tasks (Luna and Sweeney, 2004; Casey et al., 2005; Durston and Casey, 2006). After Barkley (1997) introduced his theory, much research has been devoted to investigating the development of executive control functions such as the ability to override conflict, response preparation and inhibition and its underlying neural circuitry in children with ADHD.

A task that is often used to assess different executive processes impaired in ADHD is the so-called cued-Go/Nogo task or CPT-AX task, in which subjects have to respond to a Go stimulus (e.g. the letter $X$ ) provided that it is preceded by a predefined cue stimulus (e.g. letter $A$ ), and inhibit responses on Nogo trials (letters other than $X$ that follow the cue). Several studies have shown that children, whose behavioral inhibition functioning and cognitive control is not yet fully developed, perform worse than adults in such Go/Nogo tasks. In a recent CPT-AX study, Jonkman (2006) found that young children (age 6-7) made less hits, had higher reaction 
time variability, higher Inattention and Impulsivity scores and made more errors of commission than older children (age 9-10) and adults (age 20-22). Furthermore, compared to adults they responded slower. Higher reaction times in children in a Go/Nogotask were found as well by Tamm et al. (2002) and Booth et al. (2003), and additionally, in the latter study more overall errors and especially more commission errors were made by children compared to adults.

Even though at school-age attention levels and inhibitory functioning are still immature in typically developing children, worse behavioral performance has already been reported at this stage in ADHD children. For example, larger and more variable reaction times (Banaschewski et al., 2003, 2004; Fallgatter et al., 2004; Wiersema et al., 2006a) were repeatedly found in cued Go/Nogo tasks in ADHD children between the age of 8-14 years, indicating problems to sustain attention over extended periods of time, a process that has been related to frontal lobe functioning (Stuss et al., 2003; Bellgrove et al., 2004). Furthermore, ADHD children have been found to make more false alarm (Nogo) errors than healthy children (Yong-Liang et al., 2000; Durston et al., 2003; for an exception, see: Wiersema et al., 2006a) which suggests a deficit in inhibitory functioning.

By measuring event-related brain potentials (ERPs) additional to behavioral measures in the CPT-AX task, it is possible to further specify which subprocesses are involved in deficient performance in such tasks. For example, the measurement of ERPs in the CPTAX task provides the opportunity to study executive processes that do not require an overt response such as stimulus expectation and response preparation that appear in reaction to the cue (the letter A) and processes like conflict monitoring and response inhibition in reaction to the Nogo stimulus.

ERP components that have been associated with conflict monitoring and response inhibition are the Nogo-N2 and the Nogo-P3. The Nogo-N2 is reflected by an enhanced negativity at fronto-central scalp locations in response to Nogo stimuli (relative to Go stimuli) that is seen whenever there is a conflict between the prepotent response and the currently required response. In source localization studies, the source of the Nogo-N2 has been located in the Anterior Cingulate Cortex (ACC) in healthy adults (Nieuwenhuis et al., 2003; Bekker et al., 2004) and 6- to 10-yearold children (Jonkman et al., 2007). Whereas the debate on the exact functional significance of the Nogo-N2 is still proceeding (Smith et al., 2007), there is a fair amount of studies linking the Nogo-N2 to the process of conflict monitoring (Nieuwenhuis et al., 2003; Donkers and Van Boxtel, 2004; Kenemans et al., 2005). The Nogo-N2 is followed in time by a frontal-centrally distributed Nogo-P3 positivity (relative to the Go condition) that is demonstrated in adults (Bokura et al., 2001; Bruin et al., 2001; Bekker et al., 2004; Donkers and Van Boxtel, 2004; Smith et al., 2007) and healthy 7- to 12-year-old children (Dimoska et al., 2003; Johnstone et al., 2005, 2007; Jonkman, 2006).

Whereas there has been debate concerning the functional interpretation of the Nogo-P3, multiple older and more recent studies have related the Nogo-P3 to the process of response inhibition (Karlin et al., 1969; Roberts et al., 1994; Bruin et al., 2001; Bekker et al., 2004; Donkers and Van Boxtel, 2004; Jonkman, 2006). Bruin et al. (2001) for example showed that the Nogo-P3 amplitude was enhanced when responses were more strongly primed, thus requiring stronger inhibition. In Bekker et al. (2004), the level of response preparation (CNV amplitude) in the cue-target interval appeared to be associated with Nogo-P3 amplitude. Interpretations of the Nogo-P3 relating to overlapping motor responses (instead of inhibition) have been refuted by research demonstrating that a Nogo-P3 still occurred in paradigms where no motor response was required (targets were counted mentally) as well as in paradigms in which Go and Nogo trials were not preceded by a cue
(Pfefferbaum et al., 1985). Finally, Go-P3 activity is defined by enhanced positivity in the Go (vs. Nogo) condition at centro-parietal electrode sites and has on the basis of a long history of experimental work, been associated with processes such as updating of taskrelevant information (Donchin and Coles, 1988) and attention or resource allocation (Israel et al., 1980). In the CPT-AX task enhanced Go-P3 effects have been reported in children when compared to adults (a.o. Davis et al., 2003; Jonkman et al., 2003).

Besides Nogo-N2 and P3, the cued-CPT task also permits to study preparation processes of cue-orientation and response preparation in reaction to a cue-stimulus. Fronto-central Cue-P2 and centro-parietal Cue-P3 that occur first in range as a reaction to the cue stimulus are thought to reflect processes of cue-orientation, and prestimulus target expectation (Van Leeuwen et al., 1998; Banaschewski et al., 2003; Bekker et al., 2004). The more broadly distributed contingent negative variation (CNV) subsequently seen in reaction to cues is thought to be related to response preparation processes (Rohrbaugh and Gaillard, 1983; McCallum, 1988).

Whereas several developmental studies reported the presence of Nogo-N2 and Nogo-P3 in healthy 8- to 12-year-old children (Johnstone et al., 2007; Jonkman et al., 2003), recently strong trends in the development of Nogo-N2 and P3 were reported in children between age 6 and 10 by Jonkman (2006). In healthy 6to 7-year olds, the Nogo-N2 was larger and had a more diffuse topography across frontal-parietal electrodes compared to 9- to 10 -year-old children and adults and the fronto-central Nogo-P3 was absent at this young age. The lack of a Nogo-P3 at this age was interpreted as immature response inhibition processing in early childhood. With respect to cue-processing, it was shown that the enhancement of the P2 in response to task-relevant cues (letter A) as compared to task-irrelevant cues was already present in early childhood (Jonkman, 2006). These results were interpreted as suggesting that cue-orientation or early selection processes might be fully matured in 6- to 7-year olds. In contrast, differences between adults and children were found for the Cue-P3 effect. Higher CueP3 effects (Cue $>$ Nocue) were observed in children at occipital leads. Based on earlier suggested links between Cue-P3 and the process of Go-expectation in similar paradigms (Van Leeuwen et al., 1998; Banaschewski et al., 2003; Bekker et al., 2004), these results were interpreted as showing higher Go-expectation in children. Furthermore, reduced CNV amplitudes were observed in children and this was explained by immaturity of frontal-parietal networks which are involved in response preparation processing.

Several studies have investigated EF in ADHD children in a Go/ Nogo task paradigm using ERP measures, but all these studies included children between 7- and 14-years old that were already diagnosed with ADHD. Concerning the Nogo-N2, most studies have found similar N2 activity in ADHD children as in their normal peers. For example, in children between 7- and 14-years old, Banaschewski et al. (2004), Fallgatter et al. (2004) and Wiersema et al. (2006a) found no differences in Nogo-N2 activity between an ADHD and a Control group, indicating normal conflict monitoring in ADHD. Nogo-P3 activity in the CPT-AX task has also shown harmonious results, consisting of attenuated Nogo-P3 amplitudes and diminished anteriorization in ADHD (Brandeis et al., 2002; Fallgatter et al., 2004, 2005; Wiersema et al., 2006a,b), suggesting problems of inhibition might be present in ADHD adults as well as in children between 7- and 14-years old. The parietal Go-P3 has been previously found to be reduced in ADHD children in middle and late childhood in the CPT-task, and this was interpreted as suggesting they have difficulties in updating task-relevant information (Overtoom et al., 1998). In two clinical studies including ADHD children between 7- and 14-years old, significantly reduced field power of Cue-P2/P3 has been reported. This reduced P2/P3 activity was interpreted as either impaired orienting (Van Leeuwen 
et al., 1998) or suboptimal energetical state regulation (Banaschewski et al., 2003, 2004) in the cue-target interval, causing these children to be less prepared/attentive for the upcoming task or stimulus event. The $\mathrm{CNV}$, also seen in reaction to a cue, is in most studies reported to be smaller in ADHD children (Dumais-Huber and Rothenberger, 1992; Banaschewski et al., 2003), indicating less response preparation.

The above review shows that whereas performance and ERPs in the CPT-AX task have been studied multiple times in ADHD children in middle and late childhood, not much is known about the normal and deviant development of Go/Nogo performance and ERPs in younger children. The necessity of completing this knowledge is shown by several studies using Go/Nogo tasks indicating that precisely the period from 3 to 7 years is one of very rapid change in EF and motor control (Livesey and Morgan, 1991; Dowsett and Livesey, 2000; Carlson and Moses, 2001). Also, in a recent study, Livesey et al. (2006) reported a moderate significant correlation between accuracy on the day-night task (measuring cognitive inhibition) and externalizing behavior in 5- to 6-year-old children. Moreover, as mentioned earlier, Jonkman (2006) reported several developmental changes in ERP activity associated with executive control in the CPT-AX task in healthy 6- to 7-year olds. Surprisingly however, to our knowledge, no ERP studies examining cognitive control have been performed in ADHD children below the age of 7. To fill this gap, the present study compared the ERPs and behavior of a group of 5- to 7-year-old healthy children with that of a group of children with ADHD symptoms derived from the community sample.

Taken in consideration that symptoms of ADHD are already seen in children from age 3 to 7 (Kadesjö et al., 2001; Döpfner et al., 2004) it was expected that the ADHD children would perform worse on behavioral measures of attention and inhibition compared to normal children. Previously found Nogo-N2 effects in ADHD have for the greater part shown similar activity for ADHD and control children, so no differences in Nogo-N2 activity were expected in the present study. Significant Nogo-P3 activity was not present in 6- to 7-year olds in the study by Jonkman (2006), and was therefore not expected to be found in 5- to 7-year olds. In contrast, reduced Go-P3 effects (Go > Nogo) in children with ADHD aged above seven were reported by several other CPT studies (DeFrance et al., 1996; Strandburg et al., 1996; Overtoom et al., 1998) and was therefore also expected in the present study. Cue-P2 as well as Cue-P3 effects were hypothesized to be attenuated in children with ADHD symptoms based on previous studies showing attention deficits in cue-processing in older ADHD children. No clear hypotheses could be formulated for CNV activity because of inconsistencies in previous studies.

\section{Methods}

\subsection{Subjects}

Originally, 29 subjects participated in the study (16 controls and 13 ADHD), of which two were excluded during statistical analysis due to significant outliers in behavioral measures ( 1 in the Control group and 1 in the ADHD group). The 15 children in the Control group ( 4 boys and 11 girls) were recruited from two different elementary schools. The 12 children in the group with ADHD characteristics ( 10 boys and 2 girls) were recruited via advertisements in local newspapers and on the internet. Subjects were divided in two groups based primarily on scores derived from the Child Behavior Checklist (CBCL; Achenbach, 1991) that was filled out by the parents in both groups. The $\mathrm{CBCL}$ is an instrument used for detection of externalizing and internalizing behavioral and attention problems. The ADHD group consisted of children that scored in the clinical range $(T$-score $>63)$ on internalizing (I), externalizing (E), total problem (T) and attention problem (AT) subscales of the CBCL. Kim et al. (2005) showed that a T-score of 60 or higher at the Attention Problems subscale of the CBCL resulted in a reasonable level of sensitivity $(0.72)$ or positive predictive value $(0.75)$ in the diagnosis of ADHD. The Control group consisted of children that scored in the non-clinical range on all four scales. For mean group $T$-scores on the different CBCL scales, see Table 1 . To further confirm the presence of hyperactive/impulsive symptoms, the parents and teachers of the children in the ADHD-symptom group additionally were administered the 10item Conners Abbreviated Parent-Teacher Questionnaire (Conners, 1973) via a telephone interview. The Conners ratings of four teachers are missing because of non-compliance, but all other ratings were well above the clinical cut-off score of 15 (max. score is 30) on both lists (parent-ratings: range $=24-30, \mathrm{M}=26.6, \mathrm{SD}=1.7$; teacher-ratings: range $=16-26, \mathrm{M}=20.7, \mathrm{SD}=3.4$ ). All children were free of other neurological or somatic health problems.

Mean age was 7.2 (SD 0.5) in the Control group and 6.8 (SD 0.9) in the ADHD group. The groups did not differ significantly in age $(p=.14)$.

To check for IQ, subjects were administered the Raven IQ test (Raven et al., 1983). In the Control group, IQ scores of five children are missing due to an administration error, but there were no indications of academic problems in these children as indicated by the $\mathrm{CBCL}$. Of the remaining eleven 6- to 7-year old all but one in the Control group scored at or above the 50th percentile of the norm population, except for one scoring in the 25th percentile ( $M=75$ th percentile, $\mathrm{SD}=20.9$, range $25-95$ th percentile). In the ADHD group 11 of the 12 children scored at or above the 50th percentile ( $M=75$ th percentile, $\mathrm{SD}=22.9$, range $25-95$ th percentile). IQ did not significantly differ between the two groups $(p=.74)$. Furthermore, parents' educational level was determined and did not differ between the groups. On all 1-4 (low-high education) scale, the Control group scored 2.7 (.94) and the ADHD group 3.0 (.75) (Group effect $F(1,25)=.43, p=.82$ ).

The present study was approved by the Local Ethical Committee, and prior to the study a written informed consent was obtained from the caretakers of all children according to the Declaration of Helsinki.

\subsection{Procedure}

The entire experimental session lasted $2-2.5 \mathrm{~h}$. The session started with the attachment of the electrodes. During electrode attachment children watched cartoons. During the experimental session all children sat in front of a 17-in. VGA monitor with their eyes aligned to the centre of the screen at a distance of approximately $50 \mathrm{~cm}$. The participants were instructed to minimize eye blinks and refrain from making movements during task performance. The experimental session started when all tasks were practiced until a predetermined performance criterion (80\% correct detections and less than $10 \%$ false alarms) was reached. On demand, some parents sat behind their children during the experiment. After completion of the experimental session, the children were rewarded with a present (a toy).

\subsection{CPT-AX task}

The CPT-AX task consisted of a sequence of 11 different letters $(A, B, C, D, E, F, G, H, J, L$ and $X)$. The letters were white and were presented one by one between two vertical bars at the centre of the screen on a black background. The vertical bars and the letters had a height of $2 \mathrm{~cm}$ and letters had a width of $1.5 \mathrm{~cm}$.

Subjects were instructed to press a button with their right hand when the letter $X$ appeared, but only when it was preceded by the 
Table 1

Group means of $T$-scores on CBCL internalizing (I), externalizing (E), attention (A) and total problem (T) subscales (SD between brackets) in children

\begin{tabular}{|c|c|c|c|c|}
\hline & CBCL-I & CBCL-E & CBCL-A & CBCL-T \\
\hline Control & 49.7 (6.5) range: $39-61$ & 48.0 (8.8) range: $33-61$ & 52.7 (3.7) range: $50-61$ & 47.1 (9.2) range: $26-59$ \\
\hline ADHD & 63.3 (5.5) range: $52-71$ & 72.7 (6.2) range: $64-88$ & 73.5 (4.8) range: $68-85$ & 70.7 (3.6) range: $67-81$ \\
\hline
\end{tabular}

letter $A$ ( $A-X$ sequence, Go condition). When an $A$ was followed by another letter, the prepared response had to be inhibited ( $A$-not- $X$, Nogo condition). The task was administered in four separate blocks of 124 trials each, including $24 X$ and $24 \mathrm{~A}$ stimuli (of which $12 \mathrm{As}$ and $12 \mathrm{Xs}$ were part of the $A-X(\mathrm{Go})$ sequence, $12 \mathrm{As}$ were part of $A$ not- $X$ (Nogo) sequence and $12 X$ s were presented alone, without a preceding $A$ ). Thus, the occurrence of Go and Nogo trials was equiprobable (10\% of all presentations). Total probability of $A s$ and $X s$ was comparable (20\%), since As were presented in both Go and Nogo sequences and Xs were presented in Go sequences and alone. The remaining 76 trials consisted of 6 trials of the remaining letters (48 trials), with the exception of the letter $H$, which was presented 28 times to keep the probability (23\%) comparable to that of the letters $A$ and $X$. A total trial lasted $1650 \mathrm{~ms}$, with a stimulus duration of $150 \mathrm{~ms}$ and a fixed interstimulus-interval (ISI) of $1500 \mathrm{~ms}$. Before the start of the experimental session, the task was practiced (each subject received 25 practice trials) and all subjects scored at or above $80 \%$ correct responses and had less than $10 \%$ false alarms during the practice session.

\subsection{Electrophysiological recording}

For measurement of the EEG, an electro-cap consisting of 30 tin electrodes [Fp1, Fp2, F7, F3, Fz, F4, F8, FT7, FC3, FCz, FC4, FT8, T7, C3, Cz, C4, T8, Tp7, Cp3, CPz, CP4, TP8, T5, P3, Pz, P4, T6, O1, Oz, $\mathrm{O} 2$; nomenclature according to American Electroencephalographic Society (1991)] was used. All electrodes were referenced to the left mastoid and one of the electrodes in the electro-cap (FPz) was used as ground. The vertical EOG was recorded from infraorbital and supraorbital tin electrodes placed in line with the pupil of the left eye. For measurement of the horizontal EOG, two tin electrodes were attached to the outer canthi of both eyes. All electrode impedances were kept below $5 \mathrm{k} \Omega$, with exception of EOG electrodes that were held below $18 \mathrm{k} \Omega$. Signal acquisition was accomplished using Neuroscan synamps amplifiers and Neuroscan software (version 4.1). EEG and EOG signals were continuously sampled at $250 \mathrm{~Hz}$ and digitally filtered online with a high-pass filter of $0.05 \mathrm{~Hz}$ and a low-pass filter of $50 \mathrm{~Hz}$.

\subsection{Data analysis}

\subsubsection{Behavioral measures}

Performance measures in the CPT-AX task included percentage of correct Go responses, mean reaction times to correctly detected Go stimuli, Go-reaction time variability, and percentage of false alarms. Furthermore, Impulsivity scores and Inattention scores were computed according to Halperin et al. (1988) and Overtoom et al. (1998). The Impulsivity score was calculated as the sum of fast $A$-not- $X$ errors (defined as a response to the letter following the $A$ with an RT faster than the means hit RT of a subject in the task) and slow $A$-only errors (premature responses to the $A$ with RTs longer than $1250 \mathrm{~ms}$ ) divided by the total number of $A-X$ (Go) and $A$-not- $X$ (Nogo) trials (144 trials). The Inattention score was computed as the sum of the total number of misses (no response to Go trial) and number of slow $X$-only errors (response to $X$ not preceded by $A$ with an RT higher than the mean hit RT of the subject in the task) divided by the total number of Go and $X$-only trials ( 96 trials). Finally, a signal detection analysis was performed on the behavioral data to be able to dissociate sensory sen- sitivity from response bias. Since the distribution of false alarms was skewed, we performed a non-parametric signal detection analysis (see Boice and Gardner, 1988) on the sensitivity $\left(A^{\prime}\right)$ and response bias $\left(B^{\prime}\right)$ parameters.

\subsubsection{EEG and ERP data}

The continuous EEG was divided into 496 epochs of $1850 \mathrm{~ms}$, from $200 \mathrm{~ms}$ prestimulus to 1650 poststimulus, all aligned to a baseline from -200 to $0 \mathrm{~ms}$ preceding the stimulus. First, vertical EOG artifacts (blinks) were removed from the data by applying an eye-movement correction algorithm (Semlitsch et al., 1986) provided in the Neuroscan analysis software package. Instead of using automatic procedure, for the computation of regression coefficient between VEOG and the EEG-signals at the different electrodes, adequate eye blinks were manually selected and checked. After having removed eye blinks from the EEG via the above described procedure, epochs containing artifacts or horizontal eye movements exceeding $\pm 100 \mu \mathrm{V}$ were rejected from the database. Because of the presence of relatively enhanced high-amplitude, low frequency signals in five control and all ADHD subjects, in these groups a higher criterion of $120-125 \mu \mathrm{V}$ was used. ${ }^{1}$ After running this artifact rejection procedure, accepted trials were manually checked for the presence of horizontal EOG or movement artifacts. The number of trials included in the averages of both groups is given below and was comparable. Next, average ERPs were computed separately for each subject in four different stimulus conditions: (1) Go trials (ERP to Xs preceded by $A$ ), (2) Nogo trials (ERPs to not- $X$ letters following $A$ ), (3) Cue trials (ERPs to letters $A$ summed over $A-X$ and $A$-not- $X$ categories) and (4) Nocue trials in which single letters were presented $(B, C, D, E, F, G, J, L)$ that did not precede or follow an $A$ or $X$. In the averaging procedure, only trials with correct responses (Go) or correctly rejected trials (Nogo, Cue and Nocue) were included. There was a maximum amount of 48 trials in the Go and Nogo conditions. In the Control group, the amount of artifact-free EEG epochs contained in the single-subject averages ranged from 19 to 45 trials in the Go condition (group mean $=30.13$ trials, SD 8.6) and 23-46 trials in the Nogo condition (group mean $=36.5$ trials, SD 7.5). In the ADHD group, included trials ranged from 20 to 42 trials (group mean $=30.2$ trials, SD 6.6) in the Go condition and 26-47 trials in the Nogo condition (group mean $=35.5$ trials, SD 5.6). In the Cue and Nocue conditions, all single-subject averages contained more than 53 trials; the maximum number of $A$ and other letter trials was, respectively, 96 trials and 208 trials.

For the Nogo-N2 and P3 ERP analyses, mean area amplitudes at $\mathrm{Fz}$ and $\mathrm{FCZ}$ (Nogo-N2 and Nogo-P3), and $\mathrm{Cz}$ and $\mathrm{Pz}$ (Go-P3) were computed in $20 \mathrm{~ms}$ time segments running from 120 to $580 \mathrm{~ms}$. Cue-P2 and Cue-P3 analyses were performed by computing mean amplitudes at $\mathrm{Fz}$ and $\mathrm{Cz}, \mathrm{Pz}$ and $\mathrm{Oz}$ in Cue and Nocue ERPs in, respectively, $20 \mathrm{~ms}$ and $50 \mathrm{~ms}$ segments within a time window running from 120 to $340 \mathrm{~ms}$ for P2 and from 250 to $850 \mathrm{~ms}$ for $\mathrm{P} 3$. For the $\mathrm{CNV}$, mean area amplitude was determined at $\mathrm{Fz}, \mathrm{Cz}$, $\mathrm{Pz}$ and $\mathrm{Oz}$ electrodes in one broader window from 1300 to $1650 \mathrm{~ms}$ in all subjects. Because of latency differences between the groups, it was first determined on the basis of group means

\footnotetext{
${ }^{1}$ Upon request of a reviewer we also performed the ERP-analyses with an artifact rejection criterion of $\pm 120 \mu \mathrm{V}$ in all subjects; these analyses did not influence the results in a significant way.
} 
at the relevant leads in which time segments the different ERP components were maximal. These time windows can be found in the results section. Next, mean amplitudes in the relevant windows and at relevant leads were entered in the statistical analyses.

\subsection{Statistical analysis}

\subsubsection{Behavioral measures}

For all behavioral measures in the CPT task (\% hits, mean Go-RT, Go-RT variability, \% false alarms, Inattention and Impulsivity scores, $A^{\prime}$ and $B^{\prime}$ ), group effects were tested by performing independent sample $t$-tests. Equality of variances was tested with Levene's test and, if necessary, corrections for inequality were performed and accompanying $t$ and $p$ values reported. Two-tailed significance levels of $5 \%$ were adopted.

\subsubsection{ERP measures}

To test whether there are developmental differences in cue-orientation, Go-expectation, response preparation (Cue/Nocue comparison) and conflict monitoring and response inhibition (Go/ Nogo comparison), repeated measures analyses of variance were performed for Cue-P2, Cue-P3, CNV, Nogo-N2, Nogo-P3 and Go$\mathrm{P} 3$, respectively, at the leads where the different waves are known to be most prominent (based on the literature).

For both the Nogo-N2 and Nogo-P3 analysis, a $2 \times 2 \times 2$ repeated measures analysis of variance was performed, including the within factors Leads ( $\mathrm{Fz}, \mathrm{FCz}$ ) and Stimulustype (Go, Nogo) and the between factor Group (Control, ADHD). Furthermore, a $2 \times 2 \times 2$ repeated measures ANOVA was performed for the GoP3 analysis, including the within factors Leads $(\mathrm{Cz}, \mathrm{Pz})$ and Stimulustype (Go, Nogo) and the between factor Group (Control, ADHD). For the Cue-P2 analysis a $2 \times 2$ repeated measures ANOVA with the within factor Cuetype (Cue, Nocue) and between factor Group (Control, ADHD) was performed at the Fz electrode. Cue-P3 was analyzed by a $2 \times 2 \times 2$ repeated measures ANOVA including the within factor Leads $(\mathrm{Cz}, \mathrm{Pz}, \mathrm{Oz})$ and Cuetype (Cue, Nocue) and between factor Group (Control, ADHD). CNV was analyzed in the same way as Cue-P3, but for the Leads Fz, Cz, Pz and Oz. On all repeated measures analyses of variance $p<0.05$ (two-sided) was applied. A portion of the control data has been presented elsewhere in a paper examining the typical development of ERP signatures of attention and inhibition in the CPT-AX task (Jonkman, 2006).

\subsubsection{Correlations}

Correlations between the electrophysiological measures for which Group differences were found and behavioral data were calculated by means of Pearson correlation coefficients. Furthermore, to gather information about links between symptoms of internalizing, externalizing and attention problems as measured by the $\mathrm{CBCL}$ and attention or impulsivity related behavior in the CPT-AX task, Pearson correlations were calculated also between these measures (whole group data).

\section{Results}

\subsection{Behavioral results}

Mean percentages and SDs of hits (correct Go responses), mean RT to Go stimuli (Go-RT), Go-RT variability (differences in standard deviations of RT), Inattention scores, Impulsivity scores, total amount of false alarms (\%) and non-parametric signal detection parameters $A^{\prime}$ and $B^{\prime}$ in the ADHD and normal children are presented in Table 2. Significant group effects appeared for \% hits $(F(1,25)=4.6, p=.04)$ and Inattention score $(F(1,25)=5.6$, $p=.03)$. No behavioral differences between the ADHD group and the Control group were found for the other behavioral measures
(Group effects: Go-RT: $p=.60$; Variability Go-RT: $p=.44$; Impulsivity score: $p=.81$; $A$-not- $X$ FA: $p=.45$ ). Non-parametric analyses did not change results.

Furthermore, to be able to distinguish between sensitivity and response bias, non-parametric signal detection analysis was performed and revealed that ADHD children had a lower sensitivity for detection of the target stimulus $(t(25)=-2.13, p<.05) ; A^{\prime}$ was .94 (SD 0.35) and .97 (SD 0.02) in ADHD and Control groups, respectively. The groups did not differ significantly in response bias $(t(25)=-.039, p<.96$, that was .87 (SD 0.20 and 0.25$))$ in both ADHD and Control groups.

\subsection{ERP results}

\subsubsection{Go-Nogo analyses}

Grand average ERP waves in the ADHD and Control group in Go and Nogo conditions at $\mathrm{Fz}, \mathrm{FCz}, \mathrm{Cz}$ and $\mathrm{Pz}$ are depicted in Fig. 1. Mean Go/Nogo-N2 and P3 area amplitudes and SDs at Fz and FCz and Mean Go/Nogo-P3 area amplitudes and SDs at $\mathrm{Cz}$ and $\mathrm{Pz}$ in predetermined time windows for the separate groups are shown in Table 3. Topographic maps of N2 and P3 in Go and Nogo conditions are presented in Fig. 2.

\subsubsection{Nogo-N2 effects}

Nogo-N2 activity was maximal between 320 and $360 \mathrm{~ms}$ in the normal group and between 340 and $380 \mathrm{~ms}$ in the ADHD group (Go/Nogo effects were significant in these windows with $p<.001$ at both $\mathrm{Fz}$ and $\mathrm{FCz}$ ). Mean amplitudes in the above mentioned time windows were entered in a repeated measures analysis of variance to test for Leads $(\mathrm{Fz}, \mathrm{FCz}) \times$ Stimulustype $(\mathrm{Go}$, Nogo $) \times$ Group (Control, ADHD). A 2-way interaction was found for Leads $\times$ Stimulustype $(F(1,25)=5.2, \quad p<.05)$, but no differences between the groups were found. The topographic maps show enhanced negativity in the Nogo condition (compared to Go) across fronto-central and parietal electrodes in both groups (see Fig. 2). The more widely distributed Nogo activity across parietal electrodes in both groups is in agreement with topographies reported in an earlier developmental paper in typically developing children aged 6-7 years (Jonkman, 2006).

\subsubsection{Nogo-P3 effects}

The Grand average plots were indicative of the presence of small Nogo-P3 activity between 460 and $500 \mathrm{~ms}$ in the healthy group and between 540 and $580 \mathrm{~ms}$ in the ADHD group (see Fig. 1). The analyses did however only reveal a marginally significant Stimulustype effect $(F(1,25)=4.0, p=.06)$, but no group effects, indicating very little Nogo-P3 activity was present at Fz and $\mathrm{FCz}$ in both groups. The absence of fronto-central Nogo-P3 activity (defined as larger positivity in Nogo vs. Go condition at these locations) can also be seen in the topographic maps of both Control and ADHD children, only showing parietal P3b activity (enhanced positivity in Go vs. Nogo condition) (see Fig. 2).

\subsubsection{Go-P3 effects}

Go-P3 activity at $\mathrm{Cz}$ and $\mathrm{Pz}$ was present between 580 and $800 \mathrm{~ms}$ in both groups as can be seen in the Grand average plots (Fig. 1). A repeated measures analysis revealed a significant Leads $(\mathrm{Cz}, \mathrm{Pz}) \times$ Stimulustype (Go, Nogo) interaction $(F(1,25)=9.7$, $p<.01)$. Further testing revealed a Stimulustype $\times$ Group interaction at $\mathrm{Cz}(F(1,25)=4.3, p<.05)$, due to a significant Stimulustype effect for the Control group $(F(1,14)=8.4, p<.05)$ which was absent in the ADHD group $(p=.65)$. At Pz, a main Stimulustype effect showed an enhanced Go-P3 $(p<.01)$ in both groups, but no difference between the groups was found. The topographic maps in Fig. 2 show a normal and comparable Go-P3 distribution (enhanced positivity in Go vs. Nogo condition) across centro-parietal 
Table 2

Group means (standard deviations between brackets) of the behavioral parameters in the CPT-AX task, arranged in order of attention and impulsivity measures

\begin{tabular}{|c|c|c|c|c|c|c|c|c|}
\hline & \multicolumn{4}{|c|}{ Attention measures } & \multicolumn{2}{|l|}{ Impulsivity measures } & \multicolumn{2}{|c|}{ Signal detection } \\
\hline & Hits (\%) & Go-RT (ms) & Variability Go-RT (ms) & Inattention score (\%) & Impulsivity score (\%) & $A$-not-X FA (\%) & $A^{\prime}$ & $B^{\prime}$ \\
\hline Control & $90(8)$ & $536(83)$ & $152(35)$ & $5.1(4.0)$ & $0.7(0.9)$ & $2.0(2.6)$ & $0.97(0.02)$ & $.87(0.25)$ \\
\hline ADHD & $81(14)$ & $553(82)$ & $142(30)$ & $10.1(6.7)$ & $0.6(0.7)$ & $2.8(3.0)$ & $0.94(0.35)$ & $.87(0.20)$ \\
\hline
\end{tabular}

RT, reaction time; $A$-not- $X$ FA, total amount of false alarms to Nogo stimuli.

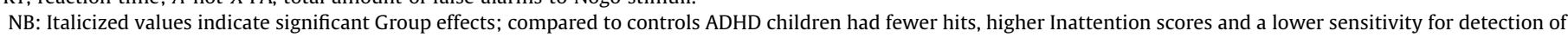
the target stimulus.

electrodes in both groups. Control children had larger central Gothan Nogo-P3 activity, which was not the case in the ADHD group (Fig. 2).

\subsubsection{Cue-Nocue analyses}

The grand average ERP waves of the ADHD and Control group in Cue and Nocue conditions at $\mathrm{Fz}, \mathrm{Cz}, \mathrm{Pz}$ and $\mathrm{Oz}$ are presented in Fig. 3. The mean amplitude and SD of the P2, P3 and CNV in Cue and Nocue conditions in the different time windows and groups are presented in Table 4. Topographic maps of P2, P3 and CNV in Cue and Nocue conditions are presented in Fig. 4.

\subsubsection{Cue-P2 effects}

The topographic maps show a similar frontal distribution of the Cue-P2 (enhanced positivity in response to cues vs. no-cues) in both groups (see Fig. 4). Cue-P2 enhancement was present in both groups and was statistically largest between 240 and $280 \mathrm{~ms}$ in the Control group, and between 260 and $300 \mathrm{~ms}$ in the ADHD group $(\mathrm{p}<0.0001$ in Control group and $p<.001$ in ADHD group; see Fig. 3). The analysis on activity in these windows showed a main effect of Cuetype $(F(1,25)=42.9, p<.00001)$, but no interaction with Group.

\subsubsection{Cue-P3 effects}

Parietal P3 effects (Cue $>$ Nocue) were largest between 450-850 $\mathrm{ms}$ in both groups (Control group $p<.001$; ADHD group $p<.05$; see Fig. 3) and Fig. 4 shows comparable centro-parietal distributions of the Cue-P3 in both groups. Repeated measures analyses including mean amplitude in these windows showed there was a Leads $\times$ Cuetype interaction $(F(1,25)=23.6, p<.00001)$. Further testing at the separate leads revealed a significant Cuetype $\times$ Group interaction at $\mathrm{Cz}(F(1,25)=5.0, p<.05)$ and $\mathrm{Pz}$ $(F(1,25)=4.6, p<.05)$. At $\mathrm{Oz}$, only a significant Cuetype effect was found $(p<.00001)$. The interaction effect at $\mathrm{Cz}$ was caused by a significant Cuetype effect in the normal group $(p<.001)$, which was absent in the ADHD group $(p=.71)$. At Pz the Cuetype effect was significant in both groups (Controls: $p<.00001$ and ADHD: $p<.01$ ), but much smaller in the ADHD group. To control for possible effects of hemispheric asymmetries, additionally, P3 activity at C3- and C4-electrodes was analyzed. This analysis did not yield any asymmetry in Cue-P3 (Electrode effects (C3-C4 difference): $p=.12$ and $p=.35$ in Control and ADHD groups, respectively) or NoCue-P3 (Electrode effects of $p=.48$ and $p=.56$ in Control and ADHD groups, respectively; see Fig. 5). The CNV analysis also did not reveal any hemisphere effects in the analysis including C3-C4 electrodes (C3-C4 difference Cue-P3: $p=.48$ and $p=.66$; C3-C4 difference Nocue-P3: $p=.95$ and $p=.15$, in Control and ADHD groups, respectively).

\subsubsection{Cue-CNV effect}

The CNV analysis revealed a significant Leads $\times$ Cuetype $\times$ Group interaction $(F(1,25)=4.4, p<.05)$. Testing at the separate leads revealed a Cuetype $\times$ Group interaction at $\mathrm{Cz}(F(1,25)=5.5$, $p<.05), \mathrm{Pz}(F(1,25)=7.0, p<.05)$ and $\mathrm{Oz}(F(1,25)=11.6, p<.01)$.
At Fz, there was a significant Cuetype effect $(p<.00001)$, but no Group difference. To further qualify the interaction, post-hoc testing was performed at the separate leads to find out whether this group difference was caused by amplitude differences in the Cue or the Nocue condition. As expected, group differences were only present in the Cue condition at $\mathrm{Cz}(p<.01), \mathrm{Pz}(p<.01)$ and $\mathrm{Oz}$ $(p<.001)$, indicating larger CNV amplitudes in the ADHD-symptom group. To account for the possible influence of preceding P3 activity (for which group differences were found at centro-parietal leads) on CNV activity, a baseline correction was performed on the individual averages using the $450-850 \mathrm{~ms}$ interval, subtracting Cue-P3 activity. Consequently, the larger Cue-CNV activity in the ADHD group was no longer present at $\mathrm{Cz}$ (Group: $p=.70$ ) or $\mathrm{Pz}$ (Group: $p=.70$ ), but still marginally significant at $\mathrm{Oz}$ (Group: $p=.08$ ). Fig. 4 shows similar CNV distributions in control and ADHD-symptom groups.

\subsection{Correlations}

\subsubsection{Correlations $C B C L$ and behavioral data}

Correlation plots for significant results are displayed in Fig. 6. Significant correlations were found between all three CBCL subscales (E, I and AT) and \% hits (coefficients between -.38 and $-.45, p$ between .02 and .05 ) on the one hand and Inattention score (coefficients between .41 and $.48, p$ between .01 and .04 ) on the other hand on the CPT-AX. The CBCL-scales did not correlate with CPT-AX Impulsivity score (coefficients between -.12 and $.03, p$ between .55 and .90 ) or \% false alarms (coefficients between -.04 and $.09, p$ between .66 and .85 ).

\subsubsection{Correlations behavioral data and Go and Cue-P3}

Correlation plots for significant results are displayed in Fig. 7. The Go-P3 effect (Go-Nogo difference score) at Pz correlated significantly (marginally significant at $\mathrm{Cz}$ ) with the behavioral attention measures \% hits $(r=.49, p<.01$ and $r=.38, p<.06$ at, respectively, $\mathrm{Pz}$ and $\mathrm{Cz})$ and Inattention score $(r=-.51, p<.01$ at $\mathrm{Pz}$ and $r=-.37, p<.06$ at $\mathrm{Cz}$ ). Go-P3 did not correlate with Impulsivity measures. The Cue-P3 effect (difference score Cue-Nocue) at $\mathrm{Cz}$ and $\mathrm{Pz}$ correlated significantly with both Attention (\% hits and Inattention score) and Impulsivity (\% false alarms and Impulsivity score) related behavioral measures. For attention measures: CueP3-\% hits; $\mathrm{r}=.52, p<.01$ at both leads; Cue-P3-Inattention score; $r=-.55 /-.51 \quad(p<.01)$ at, respectively, $\mathrm{Cz}$ and $\mathrm{Pz}$. Impulsivity scores correlated significantly with Cue-P3 at all electrodes $(\mathrm{Cz}$ : $r=-.45, p<.05 ; \mathrm{Pz}: r=-.60, p<.01 ; \mathrm{Oz}: r=-.46, p<.05)$. The percentage of false alarms only significantly correlated with central and parietal Cue-P3 (Cz: $r=-.48, p<.05$; Pz: $r=-.46, p<.05)$. No correlations between the behavioral data and the CNV effect were found.

\section{Discussion}

Much research has focused on cognitive control and attention in children with Attention-Deficit Hyperactivity Disorder (ADHD) 


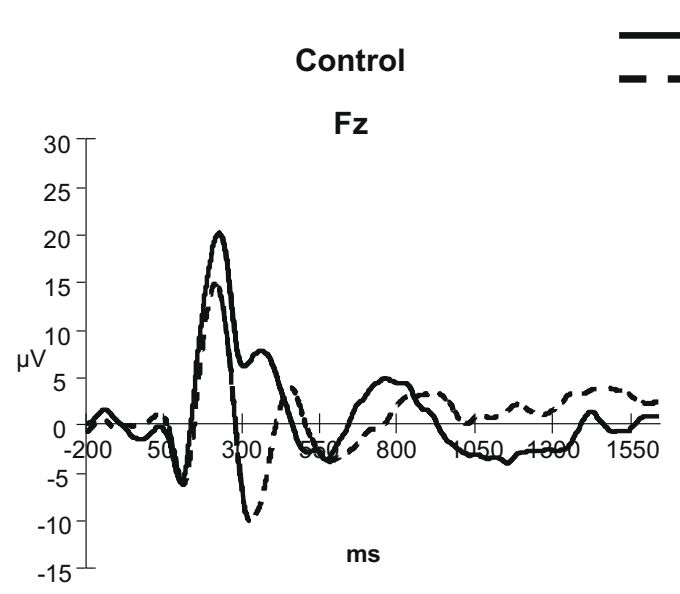

$\begin{array}{ll}\text { Go } & \text { ADHD }\end{array}$

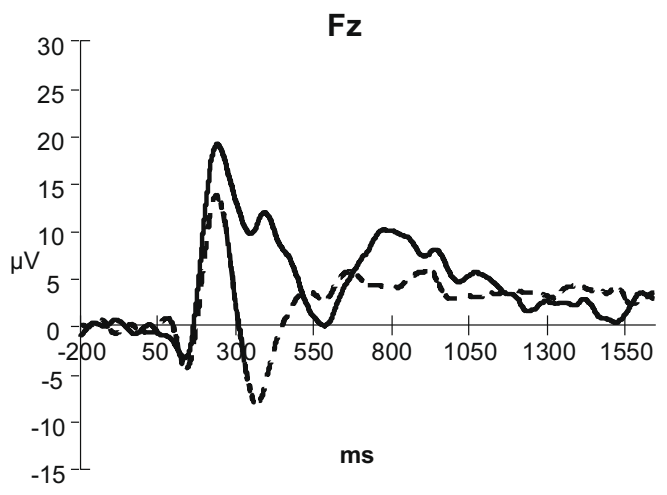

FCz

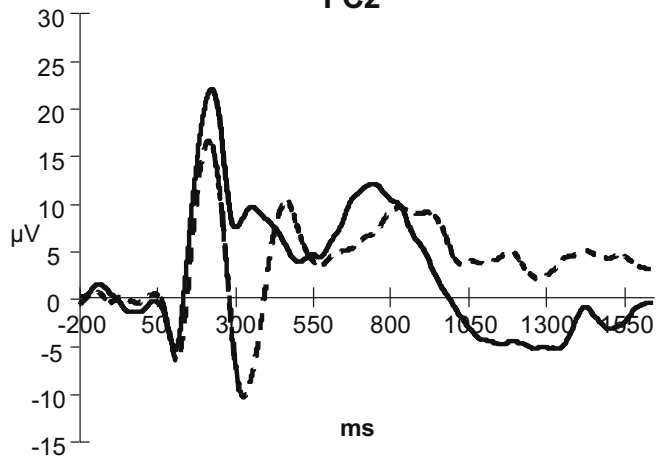

$\mathrm{Cz}$

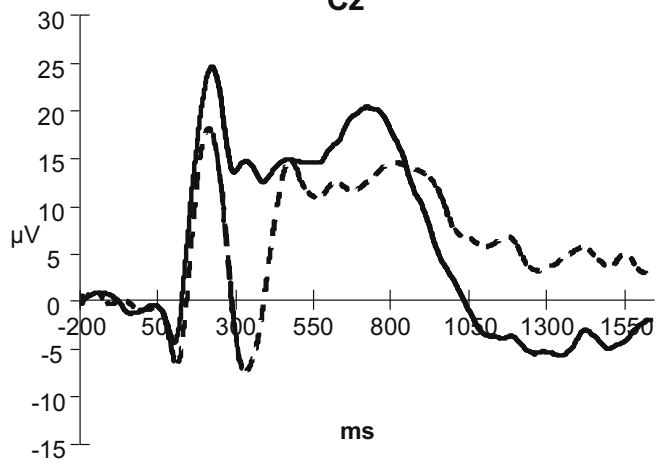

$\mathrm{Pz}$

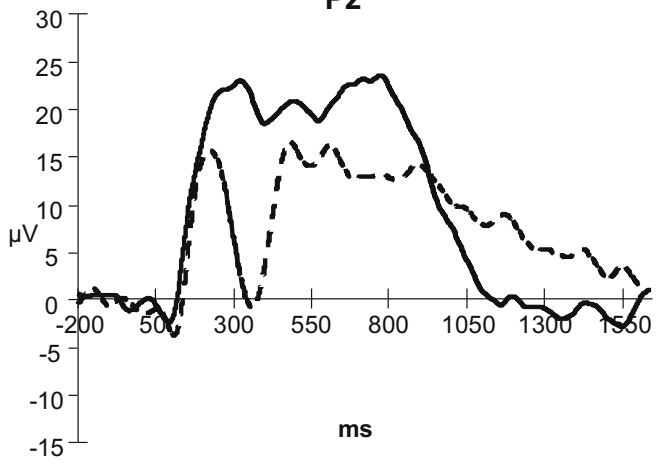

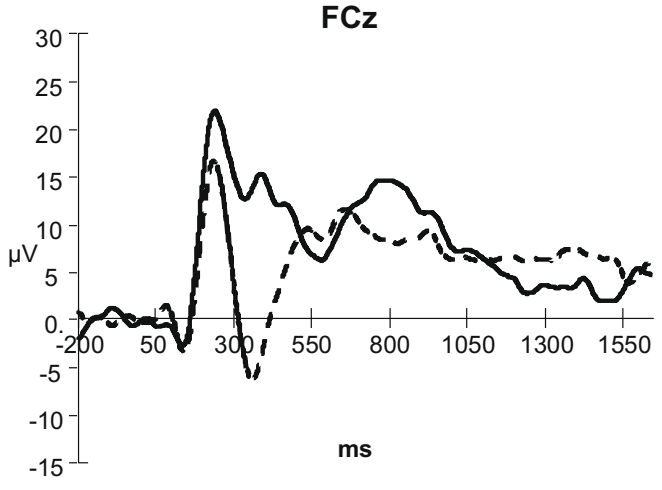

Cz
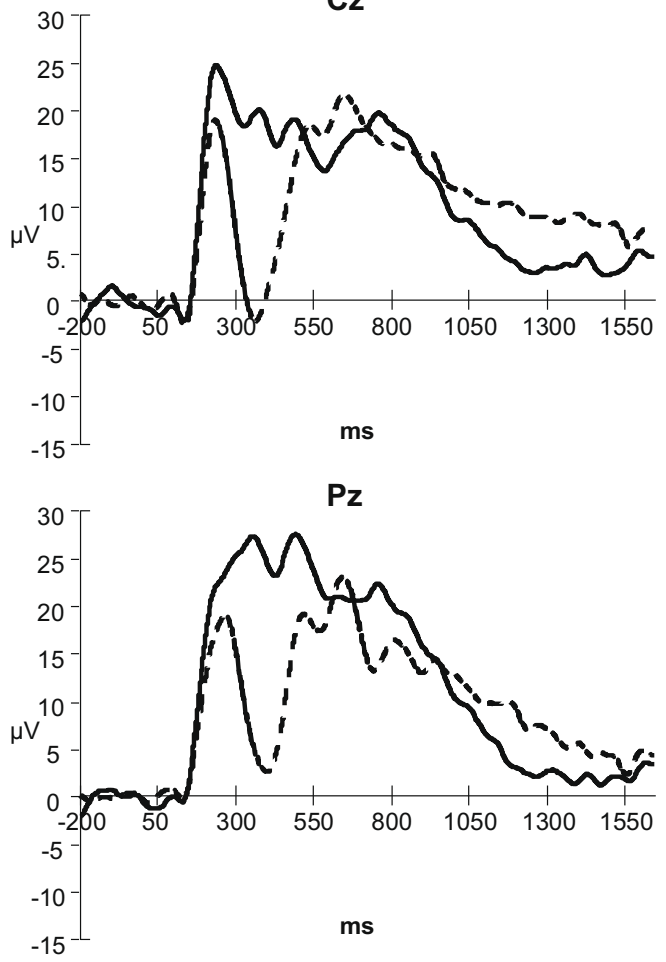

Fig. 1. Grand average ERPs of control and ADHD children in Go and Nogo conditions at four midline leads (Fz, FCz, Cz and Pz).

recently. Nevertheless, no event-related brain potential (ERP) studies examining cognitive control have been performed in ADHD children below the age of 7 , a period in which the diagnosis of ADHD is problematic. It is important to identify the symptoms, behavioral parameters and related brain abnormalities in early childhood that might be most predictive of the development of ADHD at a later age. Therefore, in the present study, performance and brain activity of young children (aged 5-7) that did or did not display symptoms of ADHD were compared. More specifically, cue-orientation, target expectation and response preparation 
Table 3

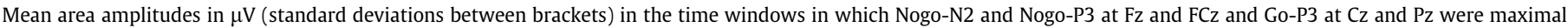
(analyses windows indicated per group in first column) in Go and Nogo conditions

\begin{tabular}{|c|c|c|c|c|}
\hline & Go & Nogo & Go & Nogo \\
\hline & $\mathrm{Fz}$ & & $\mathrm{FCz}$ & \\
\hline \multicolumn{5}{|l|}{ Nogo-N2 } \\
\hline Normal (320-360 ms) & $7.3(8.6)$ & $-9.5(10.2)$ & $9.4(11.1)$ & $-9.2(11.8)$ \\
\hline ADHD (340-380 ms) & $10.5(7.7)$ & $-7.6(8.6)$ & $14.0(6.9)$ & $-5.8(9.5)$ \\
\hline \multicolumn{5}{|l|}{ Nogo-P3 } \\
\hline Normal (460-500 ms) & $-1.5(10.3)$ & $2.5(8.9)$ & $4.6(11.6)$ & $9.4(10.2)$ \\
\hline \multirow[t]{2}{*}{ ADHD (540-580 ms) } & $0.7(10.0)$ & $3.2(7.4)$ & $6.6(11.1)$ & $9.1(8.5)$ \\
\hline & $\mathrm{Cz}$ & & $\mathrm{Pz}$ & \\
\hline \multicolumn{5}{|l|}{ Go-P3 } \\
\hline Normal (580-800 ms) & $18.7(9.0)$ & $12.7(6.7)$ & $22.3(8.7)$ & $14.0(7.1)$ \\
\hline ADHD (580-800 ms) & $17.5(10.2)$ & $19.0(9.8)$ & $21.2(11.7)$ & $18.2(8.3)$ \\
\hline
\end{tabular}

Italicized values indicate significant Group $\times$ Go/Nogo interactions; compared to controls ADHD children showed no significant Go-P3 effect at Cz.

processes evoked by a warning stimulus and subsequent conflict detection and response inhibition were examined in a Go/Nogo (CPT-AX) task by means of event-related brain potentials.

Behavioral measures revealed specific attention problems in the children with ADHD symptoms, as they had fewer correct Go responses and higher Inattention scores than control children. A signal detection analysis showed that such attention differences were not due to response biases since only the perceptual sensitivity in$\operatorname{dex} A^{\prime}$ was significantly lower in the ADHD-symptom group. Goreaction time and variability did not differ between the groups, and neither did Impulsivity score and Nogo-errors. These behavioral data suggest that already at an early age, in which it is difficult to reliably diagnose ADHD, children with ADHD symptoms have attention-related problems in the CPT-AX task. Comparable attention problems in ADHD patients were previously reported in middle and late childhood in Go/Nogo-task studies. For example, Fallgatter et al. (2004) and Yong-Liang et al. (2000) found that children with ADHD (6- to 12-years old) made more Go-errors than control children in a similar CPT-AX task. Also, higher Inattention scores were found in ADHD children aged 6-14 by Overtoom et al. (1998). Furthermore, several studies have found higher and more variable reaction times in children (Overtoom et al., 1998; Banaschewski et al., 2003, 2004; Fallgatter et al., 2004; Wiersema et al., 2006a) and in adults with ADHD (Wiersema et al., 2006b), compared to age-matched controls. The fact that such differences in response variability were not found in the present study might be due to a general immaturity of the frontal lobes in 5- to 7year-old children, causing high response variability in both groups. The frontal cortex has been shown to play an important role in deploying attention over extended periods of time and controlling performance variability (Stuss et al., 2003; Bellgrove et al., 2004). The present results indicate that reaction time variability might not distinguish children with ADHD symptoms from healthy control children in early childhood.

As mentioned earlier, behavioral measures of inhibitory control such as the percentage of Nogo-errors (false alarms) and Impulsivity score did not significantly differ between the two groups. This finding seems to be in contrast with studies reporting that ADHD
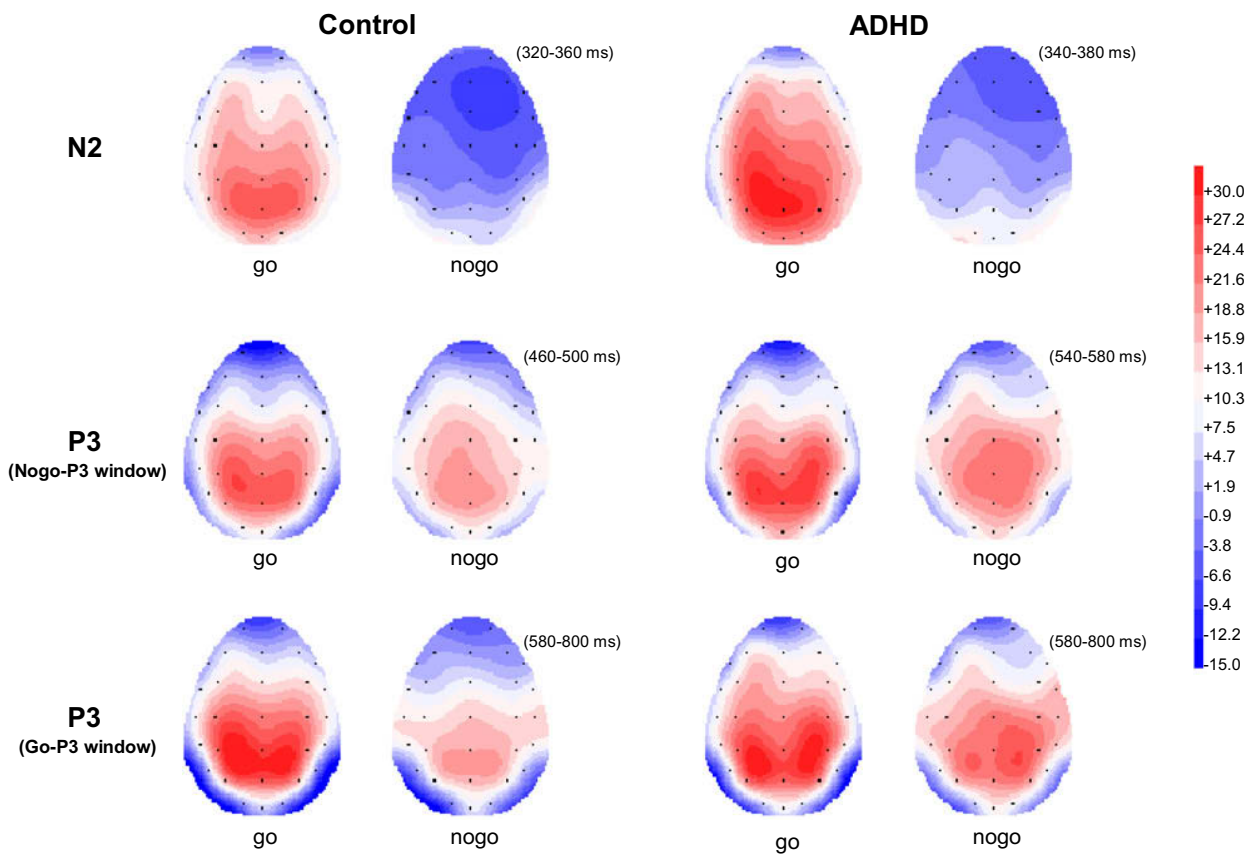

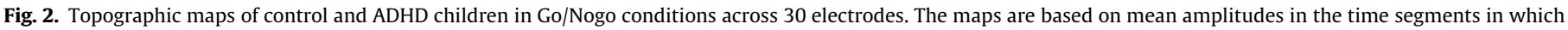
amplitudes were maximal in the different groups (see Table 3). 


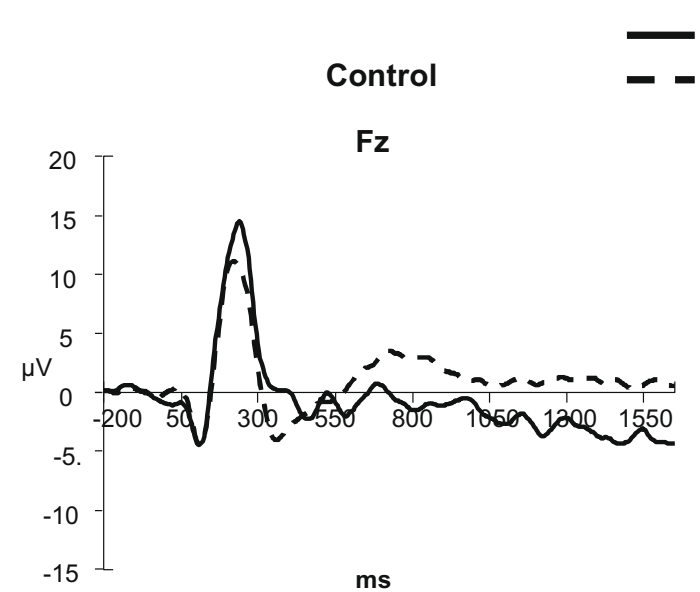

\section{Cue}

Nocue

ADHD
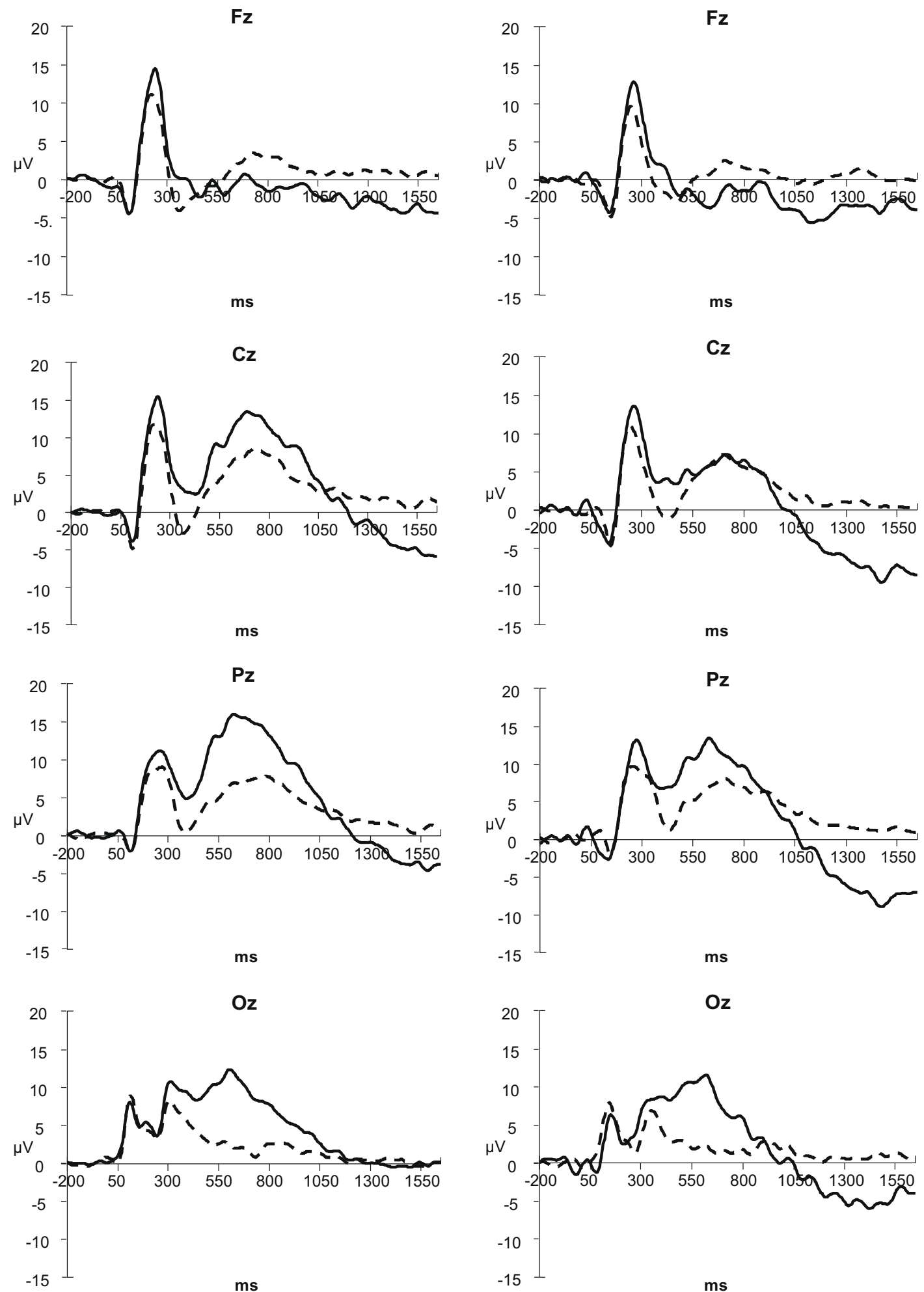

Fig. 3. Grand average ERPs of control and ADHD children in Cue and Nocue conditions at Fz, Cz, Pz and Oz leads.

patients in middle and late childhood do show inhibition related problems (enhanced number of Nogo-errors) in comparable tasks (Yong-Liang et al., 2000; Durston et al., 2003; Wiersema et al., 2006a). There was only one study that did not find a group difference in Impulsivity scores either in the CPT-AX between ADHD and control children aged 6-14 (Overtoom et al., 1998). It was hypothesized that differences in impulsivity measures besides differences in attentional measures would be found already in children below age 7, as ADHD symptoms of both inattention and impulsivity appear from the age of 3 (Kadesjö et al., 2001; Berlin et al., 2003). 
Table 4

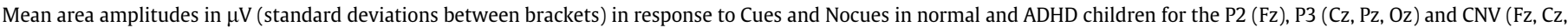
$\mathrm{Pz}, \mathrm{Oz}$ )

\begin{tabular}{|c|c|c|c|c|c|c|c|c|}
\hline & \multicolumn{2}{|l|}{$\mathrm{Fz}$} & \multicolumn{2}{|l|}{$\mathrm{Cz}$} & \multicolumn{2}{|l|}{$\mathrm{Pz}$} & \multicolumn{2}{|l|}{$\mathrm{Oz}$} \\
\hline & Cue & Nocue & Cue & Nocue & Cue & Nocue & Cue & Nocue \\
\hline \multicolumn{9}{|l|}{ P2 } \\
\hline Normal (240-280 ms) & $12.5(6.1)$ & $9.0(5.1)$ & 1 & 1 & 1 & I & l & l \\
\hline ADHD (260-300 ms) & $12.0(5.4)$ & $7.9(4.0)$ & 1 & 1 & 1 & 1 & 1 & 1 \\
\hline \multicolumn{9}{|l|}{ P3 } \\
\hline Normal (450-850 ms) & 1 & 1 & $10.6(4.0)$ & $6.5(3.0)$ & $13.9(4.8)$ & $6.6(3.8)$ & $10.0(4.5)$ & $2.6(3.9)$ \\
\hline ADHD (450-850 ms) & 1 & 1 & $5.3(5.3)$ & $4.8(2.3)$ & $9.9(4.2)$ & $6.0(2.6)$ & $9.2(4.5)$ & $2.8(3.1)$ \\
\hline \multicolumn{9}{|l|}{$\mathrm{CNV}$} \\
\hline Normal (1300-1650 ms) & $-3.4(3.5)$ & $0.8(1.9)$ & $-4.0(3.0)$ & $1.4(2.1)$ & $-2.8(3.8)$ & $1.1(1.9)$ & $0.1(2.8)$ & $0.1(1.5)$ \\
\hline ADHD (1300-1650 ms) & $-3.5(3.9)$ & $0.5(3.2)$ & $-8.3(3.6)$ & $0.6(3.5)$ & $-7.6(2.9)$ & $1.2(3.5)$ & $-4.3(2.5)$ & $0.7(2.9)$ \\
\hline
\end{tabular}

The windows in which P2, P3 and CNV were scored are indicated in the first column.

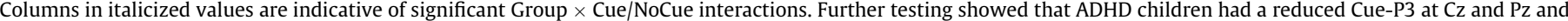
an enhanced Cue-CNV at $\mathrm{Oz}$.

However, a recent study by Smidts and Oosterlaan (2007) indicated that in preschoolers, symptoms of inattention might be better predictors of later psychopathology than symptoms of Hyperactivity/Impulsivity since the latter are reported by about $50 \%$ of the parents of 4- to 5-year-old healthy children and appear to be part of the normal behavioral repertoire at this age. This might also explain why impulsive responding was comparable between the groups in the present study.

Correlations between CPT-AX (behavioral) data and behavior as measured by the CBCL showed that attention problems in the CPTAX task were correlated with inattention symptoms. Moreover, internalizing and externalizing behavior symptoms showed an equally strong relation to attention deficits in CPT-task performance. This finding suggests that in early childhood attention deficits in the CPT-AX are not specific to children with pure attention deficits. Furthermore, it was shown that impulsivity measures in the task were not related to the children's behavior symptoms, suggesting that impulsivity measures in 5- to 7-year-old children may not be indicative for a risk of developing ADHD in a later stage.
In order to examine neural activity underlying executive control or attention deficits, several ERP components indicative of (response) preparation (Cue-P2, P3 and CNV), inhibition (Nogo-P3) and conflict monitoring (Nogo-N2) were measured. Large, and equally strong Nogo-N2 effects (Nogo > Go) were present in both groups. On the basis of prior work (Nieuwenhuis et al., 2003; Donkers and Van Boxtel, 2004; Kenemans et al., 2005; see introduction), this finding led to the conclusion that the perceived conflict that arises between the prepared and required response in the Nogo condition is similar in both groups. This is in concordance with several earlier studies reporting similar Nogo-N2 effects in older, diagnosed ADHD children and age-matched peers (Overtoom et al., 1998; Banaschewski et al., 2004; Fallgatter et al., 2004; Wiersema et al., 2006a). The present data are also in line with studies by Ridderinkhof et al. (1997) and Rueda et al. (2004) using the Flanker task, in typically developing controls, that reported the largest effects of response conflict on performance below or around the age of 7 . Johnstone et al. (2007) suggested that after 7 years of age levels of conflict reduce. This developmental
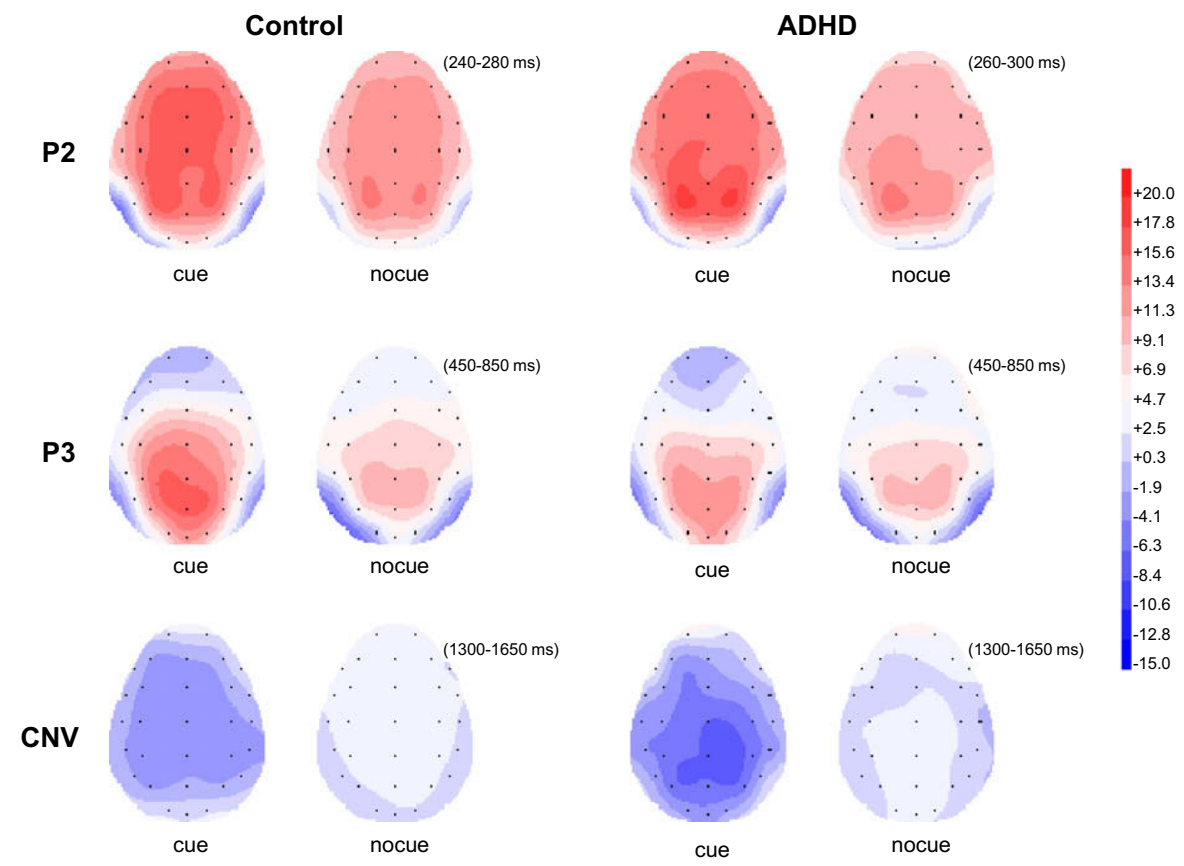

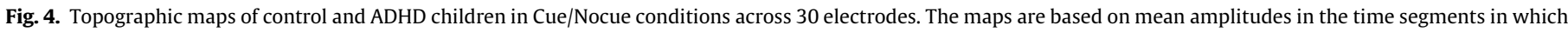
amplitudes were maximal in the different groups (see Table 4). 


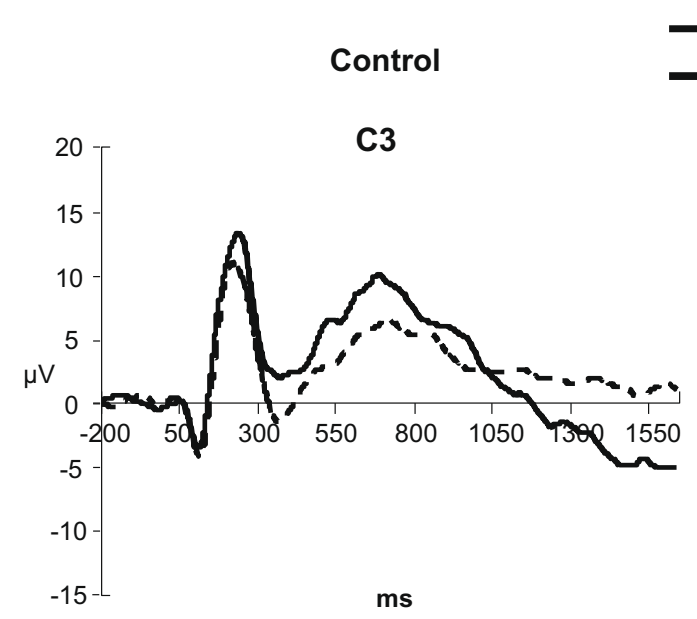

Cue

- Nocue
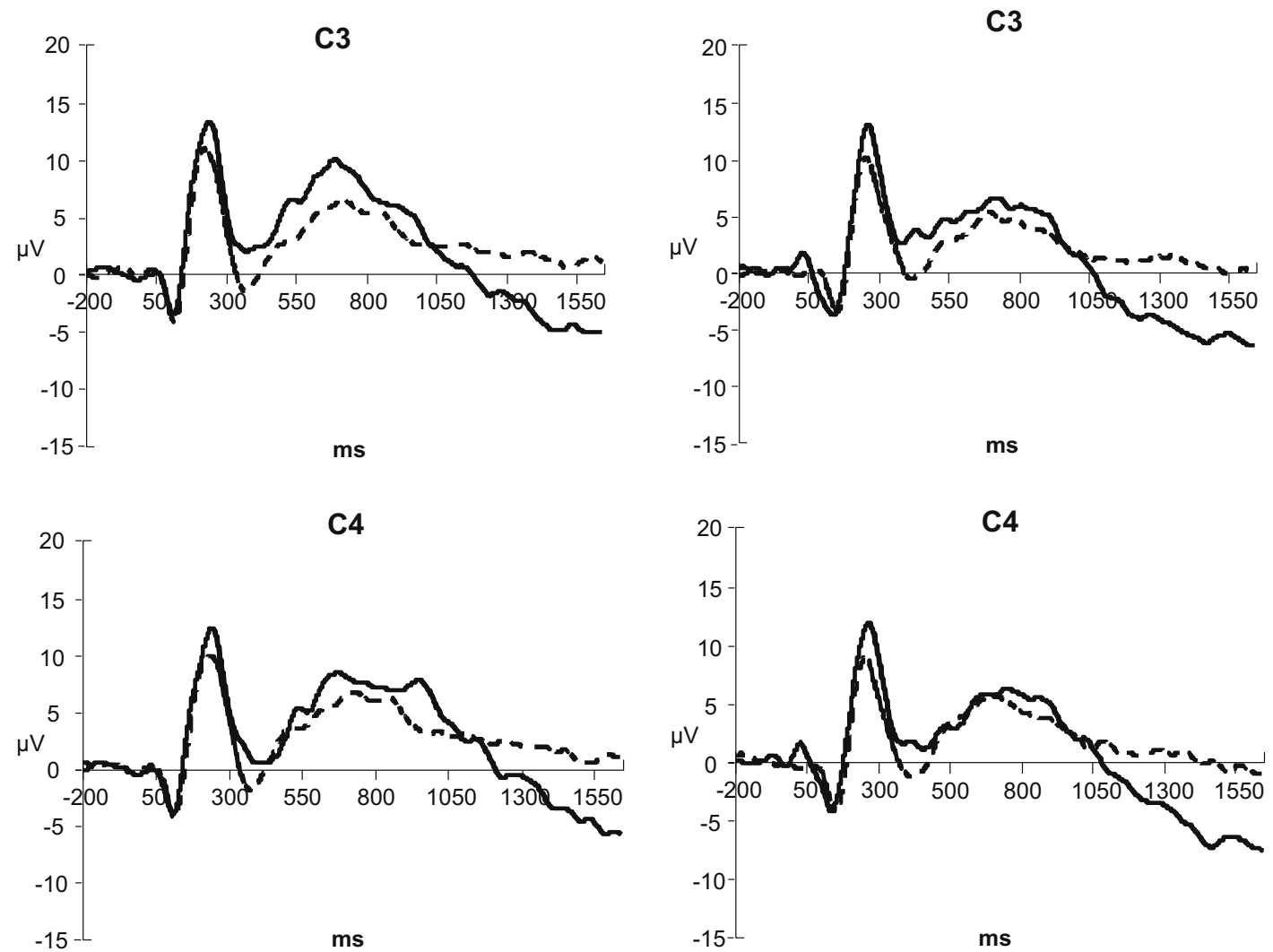

Fig. 5. Grand average ERPs of control and ADHD children in Cue and Nocue conditions at C3 and C4 electrodes.

pattern of response conflict corroborates with the strong Nogo-N2 activity found in the present study in both the ADHD-symptom group and control children. Finally, the broad topography of this
Nogo-N2 effect (being present at both fronto-central and more posterior (parietal) electrodes) is also comparable between the groups, tentatively suggesting the involvement of similar net-
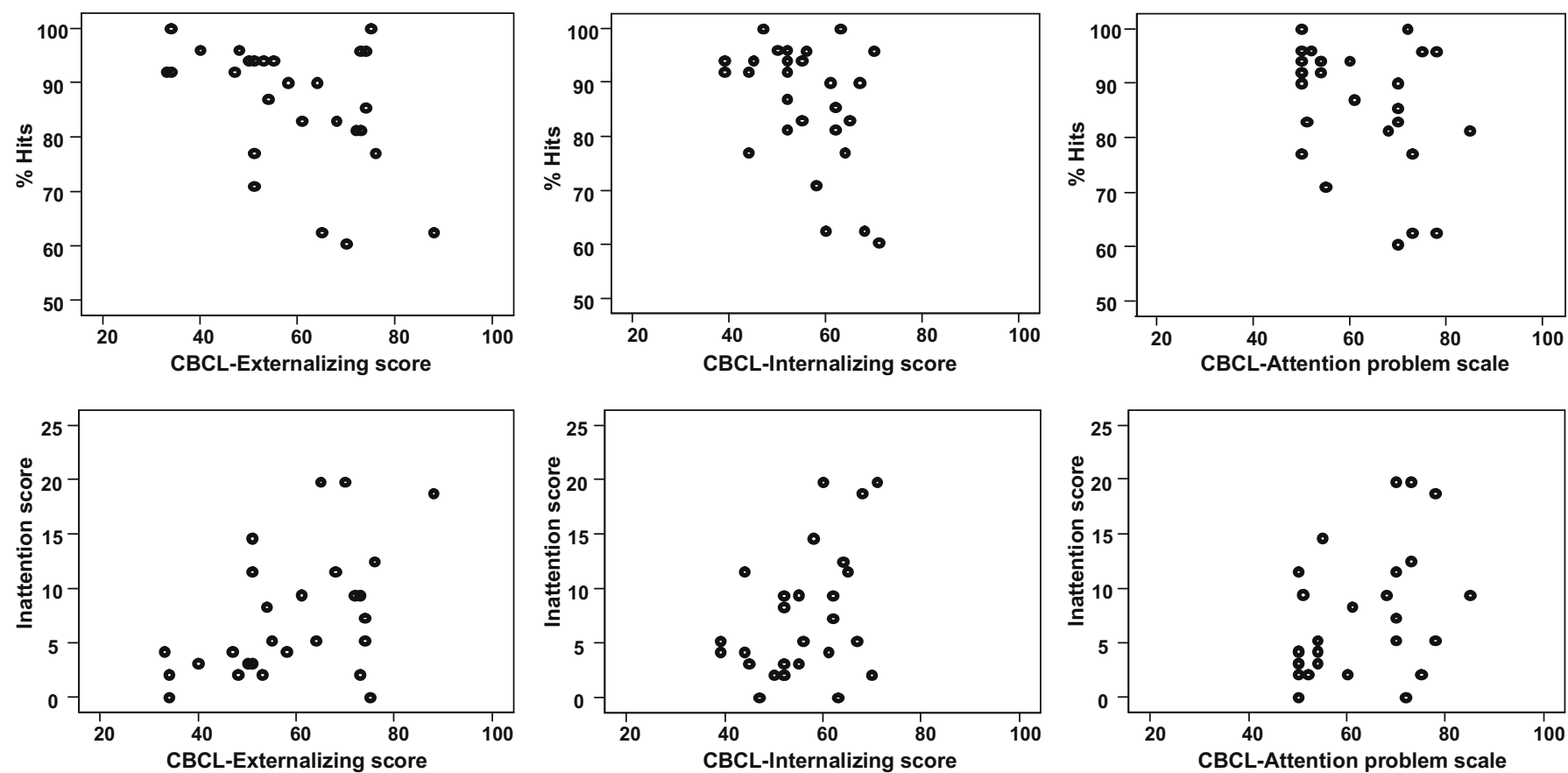

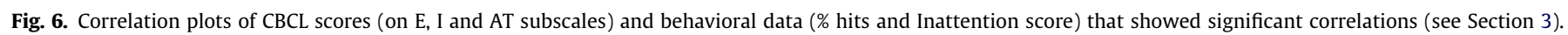



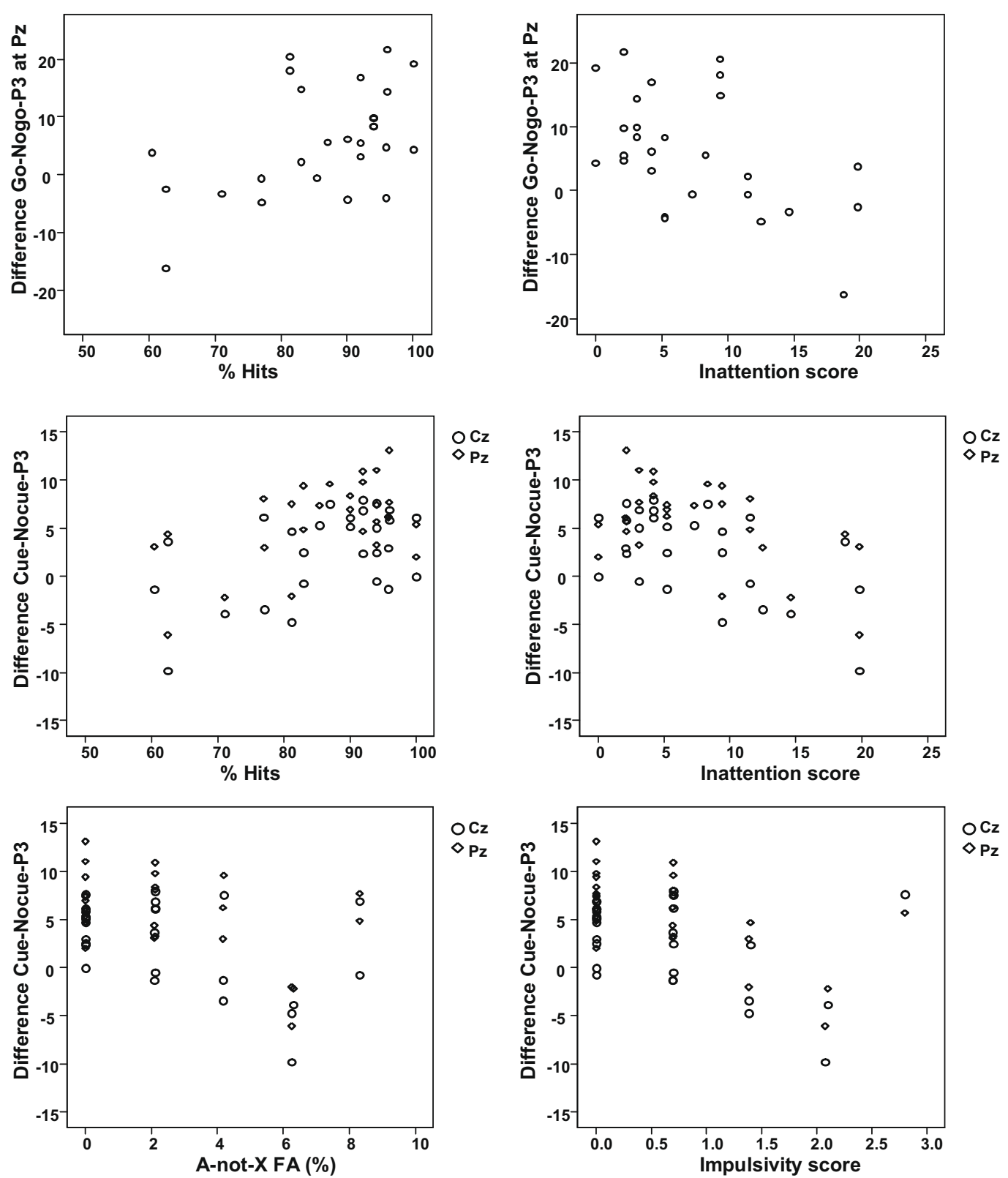

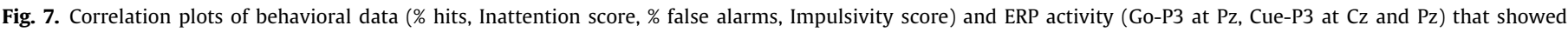
significant correlations (see Section 3).

works. This more posterior distribution was earlier reported to be specifically present in young children (compared to older children and adults) by Jonkman (2006). To explain this posterior Nogo-N2 topography during early childhood, source analysis showed that besides a commonly reported source in PFC (ACC) additional posterior sources were needed (Jonkman et al., 2007). The present study confirms that the frontal-parietal Nogo-N2 distributions during early childhood can probably be seen as a general developmental phenomenon.

The Nogo-P3 that follows the Nogo-N2 in time has been associated with the process of response inhibition in healthy adults (Bruin et al., 2001; Bekker et al., 2004; Donkers and Van Boxtel, 2004; Smith et al., 2007) and healthy 8- to 12-year-old children (Johnstone et al., 2005, 2007; Jonkman et al., 2003; Jonkman, 2006). In contrast to the clearly present Nogo-N2 effect, only a marginally significant Nogo-P3 effect (Nogo $>$ Go) could be derived from the ERP data in this study. Accordingly, a similar scalp distribution at fronto-central leads in control and children with ADHD symptoms is displayed. This was expected as Jonkman (2006) found no significant Nogo-P3 effects either in healthy 6- to 7-year olds and the present study included even younger children. The absence of a clear Nogo-P3 effect in both groups in the present study is interpreted as resulting from still immature response inhibition processes. The subjects were however capable of inhibiting their responses in the majority of the trials. Also, other studies showed that the Nogo-P3 develops relatively late, around age 10 (Okazaki et al., 2004). Reduced fronto-central Nogo-P3 activity has, however, been consistently reported in ADHD children compared to control children between 7- and 14-years old (Brandeis et al., 2002; Fallgatter et al., 2004; Wiersema et al., 2006a). Thus, due to developmental immaturity, reduced Nogo-P3 effects cannot be used as early predictors for the development of inhibitory control deficits in children with ADHD symptoms.

In contrast to the absence of processing differences in Nogo-trials, the processing of target stimuli on Go-trials did differ between the groups. The results showed the absence of a Go-P3 effect at 
central electrodes in the ADHD-symptom group, whereas a significant enhanced Go (vs. Nogo) P3 was found in the Control group. Furthermore, Go-P3 effects were specifically correlated with attentional performance measures in the sense that subjects with higher inattentive performance had lower or absent Go-P3 effects. Accordingly, the absence of a P3 effect at central leads in young (5- to 7-year old) children with symptoms of ADHD is interpreted as a reduced ability to allocate attentional resources to the task in a sustained manner, leading to occasional failures to detect target stimuli. Many studies have reported a similar reduced or absent centro-parietal P3 response (often referred to as P3b) in clinically diagnosed children with ADHD in the 7-12 age range, even when having responded correctly to target stimuli (for reviews see Barry et al., 2003; Jonkman, 2005). The relation between P3b and the ability to sustain attention across tasks is supported by animal studies showing that behavioral and brain (P3b) changes during attention tasks are mediated by Locus Coeruleus (LC)-norepinephrine (NE) innervations (for a review see Nieuwenhuis et al., 2005) that have earlier been shown to play an important role in the control of vigilance and attention processes (Aston-Jones and Bloom, 1981; Aston-Jones et al., 1991, 2000; Foote et al., 1980). The present results show that such $\mathrm{P} 3 \mathrm{~b}$ deficits are already present in 5- to 7-year-old children that have clinical scores on ADHD-related symptom questionnaires filled out by the parents and teachers.

Besides the executive functions in response to a target, processes of cue-orientation, go-expectation and response preparation were also measured in the present study by analyzing ERPs in response to Cues preceding the Go/Nogo stimuli. Children displaying ADHD symptoms and control children did not differ with respect to early cue-orientation processes, as P2 effects (Cue-P2 > NoCue-P2) were comparable between groups. Also, both groups had a similar frontal Cue-P2 distribution. This P2 positivity is generally observed in adults, and is thought to reflect early automatic sensory activation/orientation processes or early attentional selection because of its sensitivity to experimental manipulations targeting such processes (Van Leeuwen et al., 1998; Banaschewski et al., 2003; Bekker et al., 2004). The relative early development of sensory areas is thought to explain the presence of early mature cue-orientation and selection processes which are thought to be reflected by the Cue-P2 amplitude.

However, children with ADHD symptoms did display reduced centro-parietal P3 response to the Cue stimulus (the letter A in the CPT-AX task) compared to controls. Earlier studies have also found a reduced Cue-P3 in ADHD children with a clinical diagnosis between 8- and 14-years old (Van Leeuwen et al., 1998; Banaschewski et al., 2003, 2004). This reduced P3 activity was interpreted as either impaired orienting (Van Leeuwen et al., 1998 ) or suboptimal energetical state regulation (Banaschewski et al., 2003) in the cue-target interval. By varying stimulus frequency, in another study the Cue-P3 response in the CPT-AX task has been associated with the level of Go-expectancy; the higher the Cue-P3 response (vs. Nocue) the higher the expectancy of a subsequent Go trial (Bekker et al., 2004). These findings and earlier reports of the involvement of LC-NE-vigilance networks involved in the generation of P3 (Nieuwenhuis et al., 2005), might indicate that the reduced Cue-P3 response in the current ADHDsymptom group might signify a reduced ability to evoke attentional responses to a task-relevant warning event. This might cause subjects to be less prepared to detect a subsequent target stimulus. Such a hypothesis is supported by the finding that a greater percentage of hits was accompanied by higher Cue-P3 amplitudes. Furthermore, when Cue-P3 amplitudes were smaller, higher Inattention scores were found. These correlations thus confirm the hypothesis of attention deficits in 5- to 7-year-old children with ADHD symptoms. However, both Cue-P3 and Cue-P2 also correlate with behavioral measures of impulsivity, although to a somewhat lesser extent than percentage hits and Inattention score.

Finally, as expected, CNV amplitudes showed higher degrees of response preparation (Rohrbaugh and Gaillard, 1983; McCallum, 1988 ) in reaction to Go-stimuli compared to Nogo-stimuli at centro-parietal and parietal electrodes in the present study. In typically developing children mature levels of the centro-parietal CNV were found in 9- to 10-year olds (Jonkman et al., 2003), but reduced centro-parietal CNV activity was present in 6- to 7-year olds (Jonkman, 2006), which was interpreted as a sign of reduced response priming in young children caused by yet immature fronto-parietal networks involved in motor regulation. Although in the present study prestimulus target expectation was suggested to be higher in control children (as reflected by enhanced Cue-P3), this did not result in enhanced centro-parietal CNV activity that would be a sign of enhanced motor preparation (Rohrbaugh and Gaillard, 1983; McCallum, 1988). Instead, the groups showed similar levels of central and parietal CNV activity. Whereas similar levels of response preparation have also been found by Van Leeuwen et al. (1998), most studies reported smaller CNV activity near or above the motor cortex in ADHD than in control children (Banaschewski et al., 2003; Perchet et al., 2001), although at an older age. Nevertheless, greater occipital CNV activity appeared in the children with ADHD symptoms. Similar results were reported by Hennighausen et al. (2000), who also observed a trend towards increased occipital CNV activity in ADHD children between 1000 and $1500 \mathrm{~ms}$ after presentation of the cue. Such enhanced occipital late CNV activity in the ADHD-symptom group might be related to differences in sensory (preparatory) processes. In so-called S1-S2 paradigms, a warning stimulus (S1) precedes the target stimulus (S2), in a way comparable to the $A(\mathrm{~S} 1)-X(\mathrm{~S} 2)$ sequence in the present task. Grunewald-Zuberbier et al. (1978) reported that the alpha rhythm at occipital electrodes in the late S1-S2 interval was attenuated in children that were best able to visually discriminate target stimuli and was hence associated with a "predominantly sensory set". In multiple other studies stronger visual attention or stronger sensory preparation for an upcoming stimulus or ocular fixation has been associated with reduced occipital alpha activity (Mulholland, 1969, 1972; Mulholland and Peper, 1972; Pollen and Trachtenberg, 1972). The present larger occipital late CNV activity in the inattentive subjects, who were shown to be deficient in target detection, might be the result of less suppression of occipital alpha activity caused by a less strong sensory set or less visual attention for the upcoming stimulus.

There are some limitations of the current study that have to be taken into account. First, a possible confound might be that the majority of the children in the ADHD-symptom group were boys, while the Control group consisted of mostly girls. However, several studies have shown that there are no effects of gender on performance or ERPs in CPT and Stop Signal tasks (Biederman et al. 2002; Seidman et al., 2005; Liotti et al., 2007), so it is not likely that this explains the attentional deficit in the ADHD-symptom group. Another issue is that whereas mean ages were not significantly different between the groups, children were not perfectly matched on age in the present study. Future research should investigate whether the present results can be replicated with even more closely age-matched groups. A final limitation of the present study is the rather small sample size, which might have led to a reduction in power. Nevertheless, consistent and correlated attention deficits were revealed in both behavior and ERPs of the 5- to 7-year-old children with ADHD symptoms, indicating that these (as opposed to impulsivity measures) might be good predictors for the risk of developing ADHD.

Concluding, findings of attenuated parietal Go-P3 and reduced Cue-P3 activity as well as enhanced occipital CNV activity and behavioral measures of attention (correct responses and Inattention 
scores), and correlations between these measures, are all indicative of deficiencies in attention processing in 5- to 7-year-old children with symptoms predictive of a future ADHD diagnosis. Although inattention might not be a specific symptom of ADHD (as inattentive responding can be observed in several other disorders, see Overtoom et al. (1998)), inattention symptoms are known to be present early in the developmental tract in ADHD children, and do not decline as much as hyperactivity and impulsivity symptoms with increasing age (Hart et al., 1995). Also, inattention symptoms appear to be better predictors of later psychopathology than symptoms of Hyperactivity/Impulsivity that are more common in younger children (Smidts and Oosterlaan, 2007). Response inhibition does not seem to be especially affected in children with ADHD symptoms in early childhood, although indications for response inhibition deficits in ADHD have been found in older children (Nigg, 2001). Correspondingly, inhibitory control as measured by the CPTAX or similar tasks has been shown to develop relatively late in childhood (Jonkman, 2006; Johnstone et al., 2007).

\section{Acknowledgements}

This research was supported by a grant from the Netherlands Organization of Scientific Research (NWO), Open Competition programme, Grant No. 400-05-132 awarded to L.M. Jonkman. The authors thank Jolanda Stienen and Stefanie de Groot for their assistance in subject recruitment and testing.

\section{References}

Achenbach TM. Manual for the child behavior checklist/4-18. Burlington, VT: University of Vermont, Department of Psychiatry; 1991.

American Electroencephalographic Society. American electroencephalographic society guidelines for standard electrode position nomenclature. J Clin Neurophysiol 1991;8:200-2.

American Psychiatric Association. Diagnostic and statistical manual of mental disorders. 4th ed. Washington: American Psychiatric Association; 1994.

Aston-Jones G, Bloom FE. Norepinephrine-containing locus coeruleus neurons in behaving rats exhibit pronounced responses to non-noxious environmenta stimuli. J Neurosci 1981;1:887-900.

Aston-Jones G, Chiang C, Alexinsky T. Discharge of noradrenergic locus coeruleus neurons in behaving rats and monkeys suggests a role in vigilance. Prog Brain Res 1991;88:501-20.

Aston-Jones G, Rajkowski J, Cohen JD. Locus coeruleus and regulation of behavioral flexibility and attention. Prog Brain Res 2000;126:165-82.

Barkley RA. Behavioral inhibition, sustained attention, and executive functions: constructing a unifying theory of ADHD. Psychol Bull 1997;121:65-94.

Banaschewski T, Brandeis D, Heinrich H, Albrecht B, Brunner E, Rothenberger A. Association of ADHD and conduct disorder - brain electrical evidence for the existence of a distinct subtype. J Child Psychol Psychiatry 2003;44(3):356-76.

Banaschewski T, Brandeis D, Heinrich H, Albrecht B, Brunner E, Rothenberger A. Questioning inhibitory control as the specific deficit of ADHD - evidence from brain electrical activity. J Neural Transm 2004;111:841-64.

Barry RJ, Johnstone SJ, Clarke AR. A review of electrophysiology in attention-deficit hyperactivity disorder: II. Event-related potentials. Clin Neurophysio 2003;114:184-98.

Bekker EM, Kenemans JL, Verbaten MN. Electrophysiological correlates of attention, inhibition, sensitivity and bias in a continuous performance task. Clin Neurophysiol 2004;115:2001-13.

Bellgrove MA, Hester RL, Garavan H. The functional neuroanatomical correlates of response variability: evidence from a response inhibition task. Neuropsychologia 2004;42:1910-6.

Berlin L, Bohlin G, Rydell A. Relations between inhibition, executive functioning, and ADHD symptoms: A longitudinal study from age 5 to 8.5 years. Child Neuropsychol 2003;9(4):255-66.

Biederman J, Mick E, Faraone SV, Braaten E, Doyle A, Spencer T, et al. Influence of gender on attention deficit hyperactivity disorder in children referred to a psychiatric clinic. Am J Psychiatry 2002;159:36-42.

Boice R, Gardner RM. A computer program to generate parametric and nonparametric signal-detection parameters. Bull Psychon Soc 1988;26:365-7.

Booth JR, Burman DD, Meyer JR, Lei Z, Trommer BL, Davenport ND, et al. Neural development of selective attention and response inhibition. Neuroimage 2003;20:737-51.

Bokura H, Yamaguchi S, Kobayashi S. Electrophysiological correlates for response inhibition in a Go/NoGo task. Clin Neurophysiol 2001;112:2224-32.

Brandeis D, Banaschewski T, Baving L, Georgiewa P, Blanz B, Warnke A, et al. Multicenter P300 brain mapping of impaired attention to cues in hyperkinetic children. J Am Acad Child Adolesc Psychiatry 2002;41:990-8

Bruin KJ, Wijers AA, van Staveren AS. Response priming in a Go/NoGo task: do we have to explain the Go/NoGo N2 effect in terms of response activation instead of inhibition? Clin Neurophysiol 2001;112:1660-71.

Carlson SM, Moses LJ. Individual differences in inhibitory control and children's theory of mind. Child Dev 2001;72(4):1032-53.

Casey BJ, Galvan A, Hare TA. Changes in cerebral functional organization during cognitive development. Curr Opin Neurobiol 2005;15:239-44.

Conners CK. Rating scales for use in drug studies with children. Psychopharmacol Bull 1973; (Special issue, Pharmacotherapy of Children):24-9.

Davis EP, Bruce J, Snyder K, Nelson CA. The X-trials: neural correlates of an inhibitory control task in children and adults. J Cogn Neurosci 2003;15(3):432-43.

DeFrance JF, Smith S, Schweitzer FC, Ginsberg L, Sands S. Topographical analyses of attention disorders of childhood. Int J Neurosci 1996;87:41-61.

Dimoska A, Johnstone SJ, Barry RJ, Clarke AR. Inhibitory motor control in children with attention-deficit/hyperactivity disorder: event-related potentials in the stop-signal paradigm. Biol Psychiatry 2003;54:1345-54.

Donchin E, Coles MGH. Is the P300 component a manifestation of context updating? Behav Brain Sci 1988;11:357-74.

Donkers FC, Van Boxtel GJ. The N2 in go/no-go tasks reflects conflict monitoring not response inhibition. Brain Cogn 2004;56:165-76

Döpfner M, Rothenberger A, Sonuga-Barke E. Areas for future investment in the field of ADHD: preschoolers and clinical networks. Eur Child Adolesc Psychiatry 2004; $13: 130-5$.

Dowsett SM, Livesey DJ. The development of inhibitory control in preschool children: effects of "executive skills" training. Dev Psychobiol 2000;36(2):161-74.

Dumais-Huber C, Rothenberger A. Psychophysiological correlates of orienting anticipation and contingency changes in children with psychiatric disorders. J Psychophysiol 1992;6:225-39.

Durston S, Tottenham NT, Thomas KM, Davidson MC, Eigsti I, Yang Y, et al Differential patterns of striatal activation in young children with and without ADHD. Biol Psychiatry 2003;53:871-8.

Durston S, Casey BJ. What have we learned about cognitive development from neuroimaging? Neuropsychologia 2006;44:2149-57.

Fallgatter AJ, Ehlis A-C, Seifert J, Strik WK, Scheuerpflug P, Zillessen KE, et al. Altered response control and anterior cingulate function in attention-deficit/ hyperactivity disorder boys. Clin Neurophysiol 2004;115:973-81.

Fallgatter AJ, Ehlis A, Rosler M, Strik WK, Blocher D, Herrmann MJ. Diminished prefrontal brain function in adults with psychopathology in childhood related to attention deficit hyperactivity disorder. Psychiatry Res: Neuroimaging 2005;138:157-69.

Foote SL, Aston-Jones G, Bloom FE. Impulse activity of locus coeruleus in awake rats and monkeys is a function of sensory stimulation and arousal. Proc Natl Acad Sci USA 1980;77:3033-7.

Grunewald-Zuberbier E, Grunewald G, Rasche A, Netz J. Contingent negative variation and alpha attenuation responses in children with different abilities to concentrate. Electroenceph Clin Neurophysiol 1978;44:37-47.

Halperin JM, Wolf LE, Pascualvaca DM, Newcorn JH, Healey JM, O'Brien JD, et al. Differential assessment of attention and impulsivity in children. J Am Acad Child Adolesc Psychiatry 1988;27:326-9.

Hart EL, Lahey BB, Loeber R, Applegate B, Frick PJ. Developmental change in attention-deficit hyperactivity disorder in boys: a four-year longitudinal study. J Abnorm Child Psychol 1995;23:6.

Hennighausen K, Schulte-Korne G, Warnke A, Remschmidt H. Contingent negative variation $(\mathrm{CNV})$ in children with hyperkinetic syndrome an experimental study using the continuous performance test (CPT). Z Kinder Jugenpsychiatr 2000;28:239-46.

Israel JB, Chesney GL, Wickens CD, Donchin E. P300 and tracking difficulty: evidence for multiple resources in dual-task performance. Psychophysiology 1980;17:259-73.

Johnstone SJ, Pleffer CB, Barry RJ, Clarke AR, Smith JL. Development of inhibitory processing during the Go/NoGo task: a behavioral and event-related potential study of children and adults. J Psychophysiol 2005;19:11-23.

Johnstone SJ, Dimoska A, Smith JL, Barry RJ, Pleffer CB, Chiswick D, et al. The development of stop-signal and $\mathrm{Go}$ /Nogo response inhibition in children aged 7-12 years: performance and event-related potential indices. Int J Psychophysiol 2007;63:25-38.

Jonkman LM, Lansbergen M, Stauder JEA. Developmental differences in behavioral and event-related brain responses associated with response preparation and inhibition in a go/nogo task. Psychophysiology 2003;40:752-61.

Jonkman LM. Selective attention deficits in children with ADHD, a review of behavioral and electrophysiological studies. In: Gozal D, Molfese DL, editors. Attention deficit hyperactivity disorder: from genes to patients. Totowa, NJ: Humana Press; 2005. p. 255-75

Jonkman LM. The development of preparation, conflict monitoring and inhibition from early childhood to young adulthood: a Go/Nogo ERP study. Brain Res 2006;1097:181-93.

Jonkman LM, Sniedt FLF, Kemner C. Source localization of the Nogo-N2: a developmental study. Clin Neurophysiol 2007;118(5):1069-77.

Kadesjö C, Kadesjö B, Hägglöf B, Gillberg C. ADHD in Swedish 3- to 7-year-old children. J Am Acad Child Adolesc Psychiatry 2001;40(9):1021-8.

Karlin L, Martz MJ, Mordko AM. Motor performance and sensory-evoked potentials. Electroencephalogr Clin Neurophysiol 1969;28:477-82. 
Kenemans JL, Bekker EM, Lijffijt M, Overtoom CCE, Jonkman LM, Verbaten MN. Attention deficit and impulsivity: selecting, shifting, and stopping. Int J Psychophysiol 2005;58:59-70.

Kim J, Park K, Cheon K, Kim B, Cho S, Hong KM. The child behavior checklist together with the ADHD rating scale can diagnose ADHD in Korean community-based samples. Can J Psychiatry 2005;50(12):802-5.

Liotti M, Pliszka SR, Perez R, Luus B, Glahn D, Semrud-Clikeman M. Electrophysiological correlates of response inhibition in children and adolescents with ADHD: influence of gender, age, and previous treatment history. Psychophysiology 2007;44:936-48.

Livesey DJ, Morgan GA. The development of response inhibition in 4- and 5-year old children. Aust J Psychol 1991;43:133-7.

Livesey D, Keen J, Rouse J, White F. The relationship between measures of executive function, motor performance and externalizing behaviour in 5- and 6-year-old children. Hum Mov Sci 2006;25:50-64.

Luna B, Sweeney JA. The emergence of collaborative brain function: FMRI studies of the development of response inhibition. Ann N Y Acad Sci 2004;1021:296-309.

McCallum WC. Potentials related to expectancy, preparation and motor activity. In: Picton TW, editor. Handbook of electroencephalography and clinical neurophysiology: human event-related potentials. Amsterdam: Elsevier; 1988. p. 427-534.

Mulholland TB. The concept of attention and the electroencephalographic alpha rhythm. In: Evans CR, Mulholland TB, editors. Attention in neurophysiology. London: Butterworth; 1969. p. 100-27.

Mulholland TB. Occipital alpha revisited. Psychol Bull 1972;78:176-82.

Mulholland TB, Peper E. Occipital alpha and accommodative vergence, pursuit tracking, and fast eye movements. Psychophysiology 1972;8:556-75.

Nieuwenhuis $S$, Yeung $N$, van den Wildenberg $W$, Ridderinkhof KR. Electrophysiological correlates of anterior cingulate function in a go/ no-go task: effects of response conflict and trial type frequency. Cogn Affect Behav Neurosci 2003;3:17-26

Nieuwenhuis S, Aston-Jones G, Cohen JD. Decision making, the P3, and the Locus Coeruleus-Norepinephrine system. Psychol Bull 2005;131:510-32.

Nigg JT. Is ADHD a disinhibitory disorder? Psychol Bull 2001;127(5):571-98

Okazaki S, Hosokawa M, Kawakubo Y, Ozaki H, Maekawa H, Futakami S. Developmental change of neurocognitive motor behavior in a continuous performance test with different interstimulus intervals. Clin Neurophysiol 2004; $115: 1104-13$.

Overtoom CC, Verbaten MN, Kemner C, van Engeland H, Buitelaar JK, Camfferman G, et al. Associations between event-related potentials and measures of attention and inhibition on the Continuous Performance Task in children with ADHD and normal controls. J Am Acad Child Adolesc Psychiatry 1998;37:977-85.

Perchet C, Revol O, Fourneret P, Mauguiere F, Garcia-Larrea L. Attention shifts and anticipatory mechanisms in hyperactive children: an ERP study using the Posner paradigm. Biol Psychiatry 2001;50:44-57.

Pfefferbaum A, Ford JM, Weller BJ, Kopell BS. ERPs to response production and inhibition. Electroencephalogr Clin Neurophysiol 1985;60:423-34.

Pollen DA, Trachtenberg MC. Some problems of occipital alpha block in man. Brain Res 1972;41:303-14.
Raven JC, Court JH, Raven J. Manual for Raven's progressive matrices and vocabulary scales. London: HK Lewis \& Co. Ltd.; 1983.

Ridderinkhof KR, van der Molen MW, Band GPH, Bashore TR. Sources of interference from irrelevant information: a developmental study. J Exp Child Psycho 1997;65:315-41.

Roberts LE, Rau H, Lutzenberger W, Birbaumer N. Mapping P300 waves onto inhibition: Go/No-Go discrimination. Electroencephalogr Clin Neurophysio 1994:92:44-55.

Rohrbaugh J, Gaillard A. Sensory and motor aspects of the contingent negative variation. In: Gaillard A, Ritter W, editors. Tutorials in ERP research: endogenous components. Amsterdam: North-Holland; 1983. p. 269-310.

Rueda MR, Posner MI, Rothbart MK, Davis-Stober CP. Development of the time course for processing conflict: an event-related potentials study with 4 year olds and adults. BMC Neurosci 2004;5:39.

Seidman LJ, Biederman J, Monuteaux MC, Valera E, Doyle AE, Faraone SV. Impact of gender and age on executive functioning: do girls and boys with and without attention deficit hyperactivity disorder differ neuropsychologically in preteen and teenage years? Dev Neuropsychol 2005;27:79-105.

Semlitsch HV, Anderer P, Schuster P, Presslich O. A solution for reliable and valid reduction of ocular artefacts, applied to the P300 ERP. Psychophysiology 1986;23:695-703.

Smidts DP, Oosterlaan J. How common are symptoms of ADHD in typically developing preschoolers? A study on prevalence rates and prenatal/ demographic risk factors. Cortex 2007;43:710-7.

Smith JL, Johnstone SJ, Barry RJ. Response priming in the Go/Nogo task: the N2 reflects neither inhibition nor conflict. Clin Neuropysiol 2007;118:343-55.

Strandburg RJ, Marsh JT, Brown WS, Asarnow RF, Higa J, Harper R, et al. Continuousprocessing-related event-related potentials in children with attention deficit hyperactivity disorder. Biol Psychiatry 1996;40:964-80.

Stuss DT, Murphy KJ, Binns MA, Alexander MP. Staying on the job: the frontal lobes control individual performance variability. Brain 2003;126:2363-80.

Tamm L, Menon V, Reiss AL. Maturation of brain function associated with response inhibition. J Am Acad Child Adolesc Psychiatry 2002;41(10):1231-8.

Wiersema R, van der Meere J, Roeyers H, van Coster R, Baeyens D. Event rate and event-related potentials in ADHD. J Child Psychol Psychiatry 2006a;47(6):560-7.

Wiersema R, Van der Meere J, Antrop I, Roeyers H. State regulation in adult ADHD: an event-related potential study. J Clin Exp Neuropsychol 2006b;28:1113-26.

Vaidya CJ, Austin G, Kirkorian G, Ridlehuber HW, Desmond JE, Glover GH, et al. Selective effects of methylphenidate in attention deficit hyperactivity disorder: a functional magnetic resonance study. Proc Natl Acad Sci USA 1998;95:14494-9.

Van Leeuwen TH, Steinhausen HC, Overtoom CC, Pascual-Marqui RD, Van't Klooste $B$, Rothenberger $A$, et al. The continuous performance test revisited with neuroelectric mapping: impaired orienting in children with attention deficits. Behav Brain Res 1998;94:97-110.

Yong-Liang G, Robaey P, Karayanidis F, Bourassa M, Pelletier G, Geoffroy G. ERPs and behavioral inhibition in a Go/No-Go task in children with attention-deficit hyperactivity disorder. Brain Cogn 2000;43:206-324. 